\title{
Diseño de una herramienta de evaluación de apps para la educación plástica
}

Carmen Gómez Redondo

Universidad de Valladolid (España)

Ana Rico Rico

Consejería de Educación de Cantabria (España)

Olaia Fontal Merillas

Universidad de Valladolid (España) 



\title{
Diseño de una herramienta de evaluación de apps para la educación plástica
}

\section{Design of a tool of assesment of apps for arts education}

\author{
Carmen Gómez Redondo \\ Universidad de Valladolid (España) \\ carmen.gomez.redondo@gmail.com
}

Ana Rico Rico

Consejería de Educación de Cantabria (España)

anaricorico@yahoo.es

\section{Olaia Fontal Merillas}

Universidad de Valladolid (España)

ofontal@gmail.com

Fecha de recepción: 28 de marzo de 2018

Fecha de aceptación: 26 de noviembre de 2019

\section{Resumen}

El creciente uso de Apps, incluso en entornos educativos, requiere de una mirada crítica y evaluativa que permita establecer unos criterios para el diseño de Apps específicas a los fines educativos y concretamente al uso educativo en la disciplina de Educación Artística. Se presenta esta investigación cuyo objetivo principal es diseñar una herramienta para la evaluación de Apps educativas para la Educación Plástica. Para ello se realiza una investigación teórica y se consultan trabajos previos que permiten establecer los criterios para la realización de la evaluación. Tras esto se muestra la metodología de la investigación (basada en el método OEPE), el diseño del instrumento y su validación. Seguidamente se da cuenta de la implementación del diseño y su pilotaje. Los resultados obtenidos se encaminan hacia un deficiente desarrollo de los contenidos y un escaso desarrollo de la creatividad por las Apps evaluadas.

Palabras clave: Educación artística; Apps; m-learning; Educación formal; Creatividad. 
Diseño de una herramienta de evaluación de apps... - C. Gómez, A. Rico y O. Fontal

\begin{abstract}
The greater use of applications, including educational environments, requires a critical and evaluative look that allows establishing criteria for the design of specific applications for educational purposes and specifically the educational use in the discipline of artistic education. That is the reason to develop this research whose objective is to design a tool for the evaluation of Educational Applications for Arts Education. To reach this aim, a theoretical investigation is carried out and previous works that allow to establish the criteria for the realization of the evaluation are consulted. After this, the research methodology (based on the OEPE method), the instrument design and its validation are shown. Then it is given an explanation of the implementation of the design and its piloting. The results obtained lead us towards the viewpoint that there is a low development of creativity by the evaluated applications.
\end{abstract}

Keywords: Arts Education; Applications; m-learning; Formal Education; Creativity.

\title{
1.INTRODUGGIÓN
}

En los últimos años, no son pocas las experiencias basadas en $\mathrm{m}_{-}$learning desarrolladas en contextos de educación no formal ligadas al patrimonio (Brazuelo y Gallego, 2011; Vicent, 2013; Santacana y Coma, 2014; Martínez, 2014; Peña, Hidalgo y Palacios, 2015). Sin embargo, en muchas ocasiones se trata la tecnología como un elemento de apoyo a los contenidos trabajados en los museos, y no como una herramienta útil para el desarrollo de sus programas educativos (Ibáñez-Etxeberria, Asensio, Vicent y Cuenca, 2012).

En la actualidad existen a nuestro alcance multitud de Apps clasificadas por sus autores como educativas, pero ello no quiere decir que todas ellas sean de calidad. En este caso el análisis de Apps es imprescindible, y más si cabe si lo que se pretende es elevarlas a la categoría de material didáctico (Marqués, 2001).

Con la aparición, el uso masivo y el crecimiento de los dispositivos móviles, la medición de usabilidad en aplicaciones móviles se tornó un tema de investigación. Los estudios de usabilidad han sido realizados en diferentes contextos, pero recientemente se ha empezado a considerar la usabilidad en un contexto móvil. Los métodos y métricas actualmente utilizados para medir usabilidad fueron creados para aplicaciones de escritorio, sin embargo, éstos pueden no ser directamente adecuados o apropiados a entornos móviles (Asensio, Santacana y Asenjo, 2018). Uno de los desafíos a los que se enfrentan actualmente los desarrolladores consiste en identificar las variables relacionadas con el ambiente de uso (contexto móvil) que pueden impactar en la usabilidad de una App (Cuello y Vittone, 2013). En este sentido, Cacheiro (2010) proponía los siguientes estándares para valorar la calidad y estructuración de los contenidos de un sitio web: la cantidad y calidad de la información, así como la calidad técnica y estética. 
Para valorar la cantidad y calidad de la información se proponen como estándares a tener en cuenta: la estructuración clara e intuitiva de los contenidos, la corrección ortográfica y gramatical de los textos, la credibilidad del autor o responsables que dependerá de la persona física o social, la organización o institución que esté detrás y represente la web, y la usabilidad, un término que Cacheiro (2010) prefiere traducir por visitabilidad. Por otro lado, la arquitectura de un sitio web bien planificado debe estar dotada de una navegación intuitiva y sencilla, enlaces externos y actualizados, posibilidad de comunicación y contacto y ausencia de publicidad molesta. Por último, alude el autor a la evaluación de la calidad técnica y estética de un sitio web. Para ello propone como estándares el acceso y navegación rápida y fiable, el diseño claro del entorno visual y sus elementos gráficos, la capacidad para retener al navegante en su visita y la utilización de recursos novedosos.

Por lo visto hasta ahora, se están realizando grandes esfuerzos en la evaluación de la usabilidad de los dispositivos móviles y sus Apps, pero estos esfuerzos se reducen al plantearse la evaluación pedagógica, de contenidos y otro tipo de aspectos, que sí deberían ser tenidos en cuenta si lo que se pretende es dar un uso educativo a las Apps (Vicent, 2013: Prieto, 2015; Kortabitarte, Ibáñez, Luna, Vicent, Guillate, Molero y Kintana, 2017; Santacana, Asensio, López y Martínez, 2018).

Como indica Santiago (2013) los mecanismos empleados para valorar la calidad de estos recursos son insuficientes porque según el autor, la mayoría de los sistemas de evaluación se basan en una laboriosa inspección manual por parte de expertos y usuarios ante una cantidad enorme de recursos que crece día a día. Por tanto, propone una serie de parámetros para la valoración de Apps con fines educativos entre los que destacan el contenido educativo y formato específico, la pertinencia de la App al área en el que se emplea, el perfil de los usuarios, el soporte multimedia de distribución o la facilidad de uso.

Prieto (2015) establece unos criterios para la utilización y diseño de Apps móviles educativas. Argumenta que la evaluación puede realizarse a través de listas de control. Como bien refleja la autora, este sistema no contempla una graduación de cada uno de los criterios, por lo que ella considera más efectiva la evaluación a través de rúbrica. Siguiendo con la línea de Vicent (2013) propone una rúbrica de evaluación basada en: motivación, trabajo colaborativo, usabilidad y compartir.

Se estaría de acuerdo con la autora en el supuesto de que la evaluación se realizase desde una única perspectiva. En el caso de la presente investigación, lo que se persigue es el diseño de una herramienta que pueda ser utilizada para la evaluación desde varios agentes. Por ello se cree más efectiva una lista de control, que recoja los datos que permitan el análisis tanto cualitativo como cuantitativo. 
Diseño de una herramienta de evaluación de apps... - C. Gómez, A. Rico y O. Fontal

\section{METODOLOGÍA}

La metodología seguida en esta investigación se fundamenta en el método OEPE (Fontal, 2016), que se desarrolla en 7 fases de estudio, se ha seguido la estructura del método, aunque no se ha aplicado de manera sistemática ya que precisaba la adecuación de las herramientas a las especificidades de nuestra investigación.

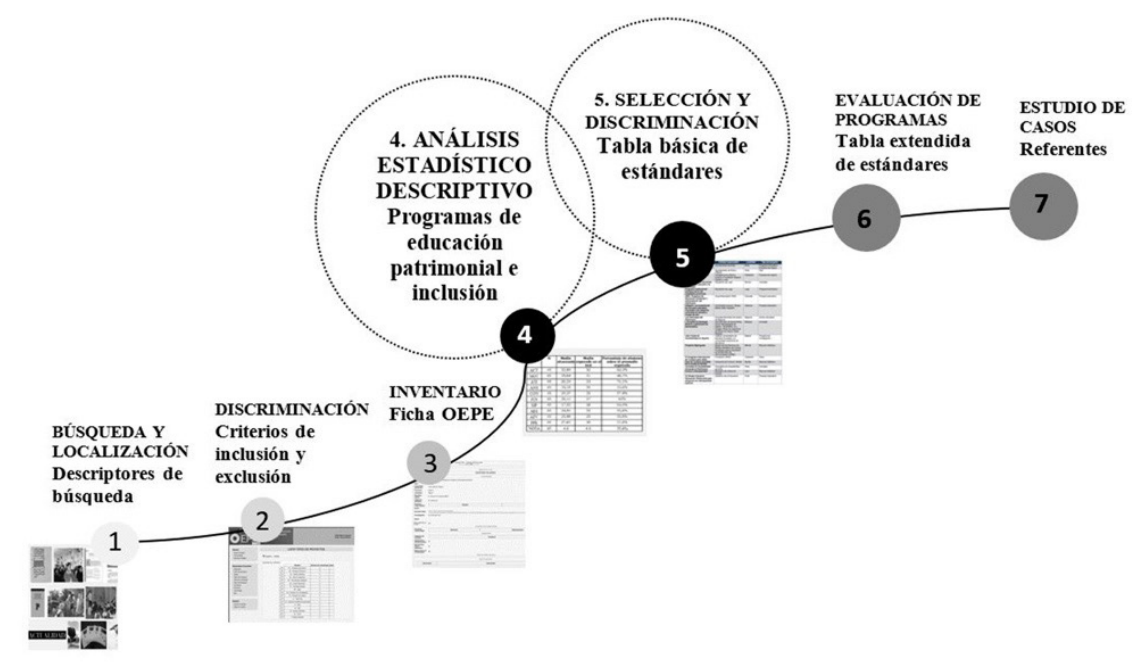

Figura 1. Síntesis del método OEPE. Fuente: Marín-Cepeda, García-Ceballos, Vicent, Guillate y Gómez-Redondo, 2017.

A continuación, se describe cómo se ha adaptado el método a esta investigación, ya que los agentes evaluadores y las herramientas varían respecto al método usado como modelo. La primera fase se centra en la búsqueda y localización de programas en base a una serie de indicadores de búsqueda definidos por el equipo de investigación y que se emplearon como términos clave de búsqueda. Dichos indicadores fueron: "Apps gratuitas" "Apps para ESO", "Edición de imágenes", "Creación de imágenes", "Animación", "Cómic" para su inventario, quedando así definido un universo de 70 Apps introducidas.

La segunda fase, de discriminación, se aplica a los programas localizados con 5 criterios de inclusión (Se pueden utilizar en ESO, Están relacionadas con los contenidos de: Educación Plástica, Imagen y Expresión, Dibujo Técnico y sirven para fomentar la creatividad) y 5 de exclusión (No son gratuitas, difícil acceso, generan desconfianza, estética infantil, no seguras en la descarga). 
Las fases tercera y cuarta se refieren al análisis, clasificación y selección en base a estándares. Para ello se diseñó una herramienta adaptada para ser una actividad de aula, en la que el alumnado analizaba una App y valoraba su adecuación a la investigación. La herramienta se centraba en seis dimensiones específicas centradas en el aprendizaje procedimental: construir conocimiento, aplicar, crear/diseñar, analizar/interpretar, describir y evaluar. Cada dimensión se dividía en varios ítems específicos de selección de respuesta múltiple (véase Anexo I).

La quinta fase consiste en la evaluación de programas. Se seleccionan los programas seleccionados del proceso de análisis anterior, y se realiza una evaluación extendida, donde se incluye una evaluación comprensiva relacionada con su tipología educativa (Stake, 2006).

Así pues, la estructura de esta investigación queda sintetizada en esta figura, en ella, se reflejan las distintas fases que han conformado esta investigación y se resalta la fase 5, en la que se centra este trabajo.

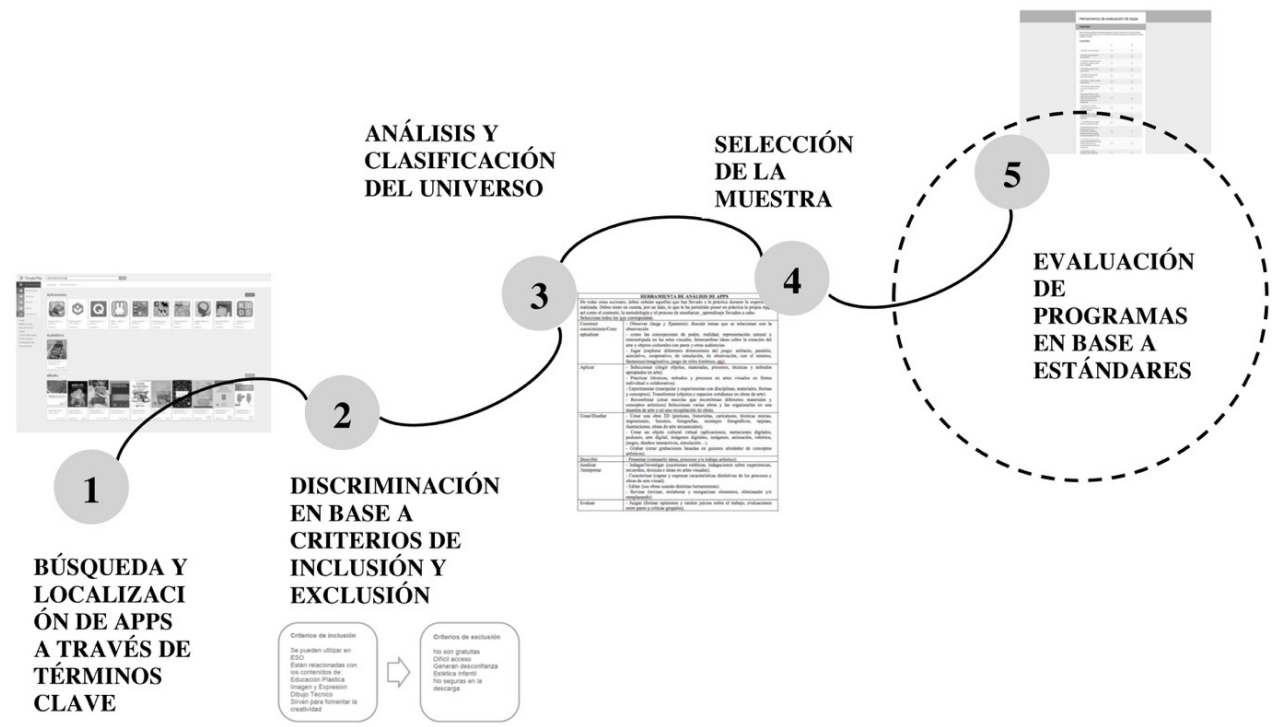

Figura 2. Síntesis del método empleado en esta investigación. Fuente: Elaboración propia.

Partiendo de la propuesta de evaluación contextualizada que propone Stake (2006) entendemos que el alumnado juega un papel fundamental y protagonista en el proceso, en este caso se ha contado con 15 alumnos de la asignatura "Imagen y Expresión" y 23 alumnos de la asignatura "Comunicación" del IES Muriedas de Cantabria, con edades comprendidas entre 14 y 16 años, ya que había algunos alumnos repetidores. Este alumnado se ha seleccionado en base a su implicación 
Diseño de una herramienta de evaluación de apps... - C. Gómez, A. Rico y O. Fontal

directa con el objeto de estudio, ya que los contenidos de las Apps evaluadas en esta investigación tratan contenidos propios de la asignatura. Su papel ha sido crítico y reflexivo y continuamente supervisado por el grupo investigador. Los resultados obtenidos por el alumnado han sido controlados y sistematizados gracias a las herramientas diseñadas en las distintas fases.

\section{DISEÑO DEL INSTRUMENTO PARA LA EVALUAGIÓN}

En este trabajo se parte de una evaluación basada en criterios y estándares, que se abordará desde el uso de una herramienta para el análisis de App y la obtención de datos. Para ello se diseña previamente a la evaluación una herramienta cuyo contenido recoge de modo explícito los criterios y los estándares de calidad (Enríquez y Casas, 2013; González-Suárez, 2011; Lowenfeld y Brittain, 1987) que servirán para la evaluación de Apps destinadas al uso didáctico en el aula (Anexo I) que puede consultarse en la web en Herramienta de evaluación de Apps. ${ }^{1}$

La herramienta resultante presenta una estructura de cinco dimensiones: Usabilidad, adecuación al contenido, metodologías activas, fomento de la creatividad desde la Educación Artística y satisfacción.

- Usabilidad (Véase Anexo II, Tabla 1)

Bajo este epígrafe se valoran el conjunto de aspectos que hacen posible que se pueda acceder fácilmente a la App y que se pueda utilizar fácilmente. A continuación, se procede a describir con detalle los criterios que debe cumplir una App para favorecer la capacidad creadora y el aprendizaje colaborativo:

Ser gratuita, con una descarga rápida y una velocidad de acceso adecuada. $\mathrm{Su}$ ejecución debe ser fiable, con un formato que pueda ser leído desde cualquier navegador. Carecer de enlaces rotos y se indique el modo de contactar con el autor. Contener enlaces a fuentes externas que puedan utilizarse para realizar reclamaciones y/o sugerencias. Además, incluir un enlace a la pantalla principal. Incluir un motor de búsqueda interno para facilitar a los usuarios la localización fácil y rápida de la información. La App debe conducir a otros enlaces de interés para ampliar la información, así como incluir un enlace al índice o tabla de contenidos. Además, incluir un enlace a la pantalla de nivel superior en la jerarquía.

El lenguaje debe ser adecuado a la edad de los alumnos y ser fácil memorizar el manejo de la App. Esa facilidad tiene que ser recordada después de utilizar la aplicación tras un tiempo.

1 Puede consultarse en: https://docs.google.com/forms/d/1V9KUwQigLonBDA_Yyrvo9n_ EtMDXy7dta1rEUIXXRWI/viewform 
La App debe contener la menor cantidad de errores posibles. Si se producen, es importante que se den a conocer al usuario de forma rápida y clara, además de ofrecer algún mecanismo para recuperarse de ese error. Tiene que contemplar posibles limitaciones físicas, visuales, auditivas o de otra índole y proporcionar un tamaño de letra ajustable o imágenes con texto alternativo.

La App tiene que poder ser transferida de un entorno a otro (diferentes dispositivos móviles). Las características del dispositivo deben permitir la utilización de la App en diferentes contextos. Si además la App, una vez descargada, no necesita conexión a Internet para poder trabajar con ella, contribuirá a más posibilidades de aprendizaje.

- Adecuación del contenido (Véase Anexo II, Tabla 2)

Estos criterios hacen referencia al tratamiento de los temas que se incluyen en la App. Esta dimensión de criterios implica que los contenidos se presenten desde la perspectiva de la disciplina a que pertenecen siendo adecuados al nivel de los estudiantes, de manera que no se produzcan aprendizajes insuficientes o concepciones erróneas.

La información sobre el momento al que pertenecen los contenidos y sobre las posibilidades de consultar informaciones más actuales invita al estudiante a la investigación y le mantiene en una situación constante de aprendizaje.

El lenguaje y la adecuación de la información seleccionada y la del medio a través del cual se transmite son aspectos clave para que haya una interacción fluida entre los estudiantes y la App. La inclusión de algún tipo de guía (del profesor, guía del alumno) resultaría beneficioso. La App debe permitir ampliar los contenidos con referencias bibliográficas u otros enlaces, y además debería contener una hoja de trabajo con actividades complementarias.

La estructura lógica de los contenidos es un criterio que hace referencia a su organización en relación con la lógica propia de la disciplina a que pertenecen. $\mathrm{Si}$ los contenidos tienen una secuencia lógica se favorece la transferencia.

El interés de los contenidos de una App se mide por la capacidad de sorprender y ofrecer una información nueva, y por la importancia que tienen dentro de la disciplina a la que pertenecen. Se trata de evitar que un material incluya contenidos evidentes que no generen aprendizaje. Respecto a la importancia, es preciso valorar que los contenidos sean relevantes y que ocupen un espacio reconocido dentro de la disciplina a que pertenecen.

\section{- Metodologías Activas (Véase Anexo II, Tabla 3)}

Lo que caracteriza una App con finalidad educativa es el aprendizaje que puede hacer el alumnado de unos contenidos y unas habilidades determinadas. El hecho de que una App se considere un material educativo implica que se 
Diseño de una herramienta de evaluación de apps... - C. Gómez, A. Rico y O. Fontal

tenga que hacer un análisis desde la perspectiva pedagógica, que se valore la capacidad para que el usuario aprenda.

Las actividades deben contener un mapa de navegación y breve descripción, así como estar en relación directa con los objetivos y contenido además de ser motivadoras. Deben fomentar la creatividad, la exploración y favorecer la transferencia. Deben tener un enfoque aplicativo-creativo y permitir que los alumnos escojan las actividades a realizar y muestren los resultados. La App debe dar información sobre los errores cometidos y orientar a los estudiantes sobre la secuencia de aprendizaje. Permitir comparar los resultados de todos los alumnos y proponer tareas ejercicios con varias soluciones válidas, además de permitir la corrección de errores. Si contiene actividades de autoevaluación éstas deberían mostrar varios formatos de presentación de respuestas (elección múltiple, Verdadero/falso, etc.)

La necesidad de establecer itinerarios de aprendizaje personales y de acceder a aspectos concretos de la App implica que los contenidos se deban organizar de forma modular. Esto quiere decir que el conjunto del contenido no ha de tener necesariamente una estructura lineal, de manera que los contenidos de un apartado no han de ser imprescindibles para pasar al siguiente. Debe existir la posibilidad de controlar la secuencia de laApp, así como la posibilidad de retomar la actividad en el punto donde se ha abandonado. Si los contenidos de la App se presentasen de manera lineal, deben tener un nivel de dificultad distribuido correctamente.

La posibilidad de modificar el itinerario de aprendizaje añadiría comodidad al uso de la App permitiendo adecuarlo a las necesidades específicas de cada estudiante. La selección de un itinerario de aprendizaje adecuado implica que haya un esquema o una guía del contenido total de la App y que se especifiquen las maneras de trabajar que existen.

Las App deben fomentar la participación del profesor, dando cabida a la manipulación del contenido. Tienen que poseer distintas fórmulas de interacción para fomentar la interactividad individual, grupal, instrumental.

La App debe informar sobre los objetivos didácticos y sus apartados, de manera que los alumnos sepan en cada momento qué se espera que aprenda al trabajarlos. Presentar o potenciar algún valor o permitir modificar actitudes como la cooperación. Las App deben facilitar las asociaciones libres de ideas y elementos y exigir o permitir observar, comparar, clasificar, ordenar, visualizar y el desarrollo de destrezas perceptuales.

- Criterios que fomentan la creatividad desde la Educación Artística (Véase Anexo II, Tabla 4)

Se han seleccionado propuestas didácticas desde los nuevos enfoques para trabajar desde m_learning, que a su vez están basados en los fundamentos 
de Lowenfeld y Brittain (1984). En el caso de la creatividad las estrategias didácticas de la App deben fomentar el libre descubrimiento y permitir las siguientes funciones: ejercitar habilidades, instruir, informar, motivar, explorar, entretener, experimentar, resolver problemas, crear, expresarse, evaluar o procesar datos. Entre los objetivos pedagógicos que debería contener la App deberían incluirse los que permitan enseñar destrezas, promover debates, estimular la imaginación, informar o aprender conceptos.

\section{- Criterios de Satisfacción (Véase Anexo II, Tabla 5)}

En esta dimensión se han tomado como referencia algunos criterios de las propuestas de Enríquez y Casas (2013), así como otros que se derivan del análisis de herramientas.

Los atributos subjetivos están relacionados con el factor humano. La satisfacción se refiere a la actitud de los alumnos hacia el uso de la aplicación. Esta dimensión está vinculada a las emociones y por lo tanto son más difíciles de medir y cuantificar. Los alumnos deben disfrutar mientras utilizan las Apps.

También se refiere la facilidad con la que los alumnos alcanzan objetivos específicos la primera vez que utilizan la App. La primera experiencia que tiene los estudiantes con un nuevo sistema es la de aprender a usarlo. Los alumnos tienen que sentirse satisfechos con la interfaz, el texto, el sistema de navegación y los menús, y, sobre todo mientras están aprendiendo a usarla.

Resulta también deseable que las Apps presenten entornos originales, bien diferenciados de otras, y que utilicen las crecientes potencialidades de las tecnologías, de manera que resulten intrínsecamente potenciadoras del proceso de aprendizaje, favorezcan la asociación de ideas y la creatividad, permitan la práctica de nuevas técnicas, la reducción del tiempo y del esfuerzo necesarios para aprender y facilitar aprendizajes más completos y significativos.

Para motivar al estudiante en este sentido, las actividades de las Apps deben despertar y mantener la curiosidad y el interés hacia la temática de su contenido. También conviene que atraigan a los profesores y los animen a utilizarlos. Una buena App debería tener en cuenta las características iniciales de los estudiantes a los que van dirigidos (desarrollo cognitivo, capacidades, intereses, necesidades) y los progresos que vayan realizando. Los contenidos deben ser significativos para los estudiantes y estar relacionados con situaciones y problemas de su interés.

Una App debe permitir resolver tareas en un tiempo limitado y completarlas con éxito en un primer intento. Además, debiera permitir aprender varias tareas en cada exploración. El tiempo destinado en una primera exploración tendría que permitir obtener resultados positivos. El tiempo empleado en completar una tarea tendría que ser proporcional a la calidad del producto obtenido. Por último, una App debería ser fácil y agradable de utilizar. 
Diseño de una herramienta de evaluación de apps... - C. Gómez, A. Rico y O. Fontal

3.1. Validación de la herramienta de evaluación.

Como explica Soriano (2014), la secuencia lógica para diseñar un instrumento de investigación con fines de medición se divide en varias fases. La primera de ellas abarca las consideraciones teóricas y objetivos de la investigación, la segunda se fundamentaría en la validación de expertos, y una tercera fase, sería la selección de la muestra para la prueba piloto.

En el presente caso, se ha generado una herramienta para la validación por expertos (Véase Anexo III). Dicha herramienta es multidimensional ya que con ella se pretende medir más de un atributo, cada característica/atributo es conceptualizada como parte de una escala común de aceptabilidad. Se utiliza una lista de control para cada una de las características, marcando una casilla dentro de una escala dicotómica.

La herramienta de validación se presentó a los expertos a través de la herramienta de Formularios de Google Drive, que permite crear formularios online, y además realiza el conteo de manera automática. Soriano (2014) recomienda claridad de los conceptos sobre el constructo teórico, medición, confiabilidad y validez para la elaboración de los instrumentos y afirma que la validez no es una propiedad intrínseca de los instrumentos, sino que dependerá del objetivo de la medición, la población y el contexto de aplicación. De ello deduce que un instrumento puede ser válido para un grupo en particular, pero no para otros.

Una vez finalizada la primera redacción del cuestionario diseñado para esta investigación, ésta se sometió a un juicio de expertos. "Los expertos son personas cuya especialización, experiencia profesional, académica o investigativa relacionada al tema de investigación, les permite valorar, de contenido y de forma, cada uno de los ítems incluidos en la herramienta" (Soriano, 2014, p. 25).

Para el juicio de expertos se toma como referente a Cabero y Llorente (2013) que propone los siguientes criterios de selección respecto a la evaluación de TIC:

- Haber realizado algún estudio teórico o empírico sobre las TIC.

- Ser docente de acciones formativas del profesorado en relación con la utilización educativa de las TIC.

- Ser profesor de los niveles educativos a los cuales la TIC va a ser aplicada, o ser un profesor que utiliza frecuentemente las TIC en la enseñanza.

El grupo de expertos que se definió estaba formado por los integrantes del departamento de Plástica del IES Muriedas de Cantabria. Entre sus miembros se precisó la colaboración de 3 profesoras de Educación Plástica y Audiovisual, Dibujo Técnico e Imagen y Expresión en distintos niveles. Además, una de ellas es la coordinadora TIC del centro. Fuera de ese contexto educativo también fue de gran ayuda la colaboración de otros profesionales especialistas como una persona licenciada en Psicología y psicopedagogía, 1 arquitecto, 1 trabajadora social, 1 
licenciada en pedagogía y educación social, todos ellos relacionados con el ámbito artístico y educativo.

La estrategia del juicio de expertos se realizó a través de lo que Cabero y Llorente (2013) denomina agregación individual, consistente en la obtención de la información de manera individual de cada uno de los expertos, sin contacto entre ellos. La información se envió a través del correo electrónico. Las pautas dadas consistieron en explorar durante un mes las Apps e intentar aprender a utilizarlas a través del aprendizaje por descubrimiento. Posteriormente se facilitó una plantilla de evaluación para analizarlas, con el fin de obtener una respuesta sistemática para la validación del instrumento. Esta plantilla presentaba los siguientes criterios:

1. Adecuación de las preguntas del cuestionario a los objetivos de la investigación.

2. Existencia de una estructura y disposición general equilibrada y armónica.

3. No se detecta la falta de ninguna pregunta o elemento clave.

4. No reiteración de preguntas, o existencia de alguna superflua. Verificar la adecuación de la longitud

5. Comprobación de cada ítem por separado: carácter, formulación, alternativas, función en el cuestionario, etc.

Finalmente, las aportaciones de la validación por expertos se recogen en la tabla 1.

Como se puede observar las principales aportaciones de los expertos giran en torno a la gramática y redacción de los apartados y en la modificación o eliminación de ítems repetitivos. Estas valoraciones fueron aplicadas a la herramienta.

\subsection{Muestra}

En un primer acercamiento al universo para la selección de una muestra, se empleó el buscador de Apps de Google procediendo primeramente con descriptores muy generales como "Apps educativas" que arrojó aproximadamente 613.000 resultados y "Apps didácticas" que arrojó 601.000 resultados.

El siguiente paso fue acotar el universo, ya que éste se centra en el contexto formal, por lo que se añadió a los descriptores de búsqueda el término "Secundaria". Se utilizaron también descriptores que contuviesen términos relacionados con el arte y con el desarrollo de la creatividad, y por último se hace referencia al desarrollo del espíritu emprendedor.

- Apps educativas para secundaria: aproximadamente 551.000 resultados.

- Apps artísticas: aproximadamente 601.000 resultados.

- Apps artísticas para secundaria: aproximadamente 231.000 resultados. 
Diseño de una herramienta de evaluación de apps... - C. Gómez, A. Rico y O. Fontal

Tabla 1. Resultados de la validación por expertos. Fuente: Elaboración propia.

\begin{tabular}{|c|c|}
\hline ITEMS A MODIFICAR & ITEMS SOBRE SUGERENCIAS \\
\hline \multicolumn{2}{|l|}{ RESPECTO A LA DIMENSIÓN DE USABILIDAD } \\
\hline $\begin{array}{l}\text { - Errores de redacción por falta de claridad en la } \\
\text { redacción o finalidad de la evaluación. } \\
\text { - Ítems número } 10,18 \text { y } 28 \text { tienen erratas. } \\
\text { - Corregir erratas en ítems números } 10,17 \text { y } 19 . \\
\text { - Falta de concordancia en número entre los } \\
\text { términos utilizados. } \\
\text { - En el ítem número } 19 \text { observar uso del artículo. } \\
\text { - Añadir artículos a ítems } 4,5,21,25,26,29 \text { y } 31 \text {. }\end{array}$ & $\begin{array}{l}\text { - La rapidez de la descarga depende más de la red } \\
\text { utilizada, que de las características de la propia } \\
\text { App. Por lo tanto, no incluiría este ítem. } \\
\text { - Mejorar redacción en los ítems número } 16,19 \text { y } \\
31 .\end{array}$ \\
\hline \multicolumn{2}{|l|}{ RESPECTO A LA DIMENSIÓN DE CONTENIDO } \\
\hline $\begin{array}{l}\text { - Errores de redacción por falta de claridad en la } \\
\text { redacción o finalidad de la evaluación. } \\
\text { - Ítems número } 10,12,23,24,25 \text { y } 26 \text { con erratas } \\
\text { - Separar pregunta } 24 \text { de la } 25 \text {. }\end{array}$ & $\begin{array}{l}\text { - Se pueden resumir algunos ítems sobre autor } \\
\text { producción etc. } \\
\text { - Cambiar el orden de los apartados: } 1,2,3,15,16 \text {, } \\
17,18,19,20,27,28,29,30,8,5,11,12,13,9,4,6 \text {, y } 7 \text {. }\end{array}$ \\
\hline \multicolumn{2}{|l|}{ RESPECTO A LA DIMENSIÓN PEDAGÓGICA } \\
\hline $\begin{array}{l}\text { - Errores de redacción por falta de claridad en } \\
\text { la redacción o propósito de la evaluación en los } \\
\text { ítems números } 9,19,20,21,22,23,24,26,27,28 \text {, } \\
32,35,36,37,38,39,55 \text { y } 90 \text {. }\end{array}$ & $\begin{array}{l}\text {-Ítem número 66: revisar el orden de posición de } \\
\text { esta pregunta. } \\
\text {-ítems desde el } 65 \text { al } 76 \text { debieran ordenarse como } \\
\text { sub-preguntas; también de la } 77 \text { hasta la } 82 \text { e } \\
\text { igualmente de la } 83 \text { a la } 89 \text {, de la } 90 \text { a la } 92 \text { y, } \\
\text { finalmente, de la } 93 \text { a la } 101 . \\
\text { - Sintetizar el número de preguntas, algunas muy } \\
\text { similares. }\end{array}$ \\
\hline \multicolumn{2}{|c|}{ RESPECTO A LA DIMENSIÓN DE CREATIVIDAD DESDE LA EDUCACIÓN ARTÍSTICA } \\
\hline $\begin{array}{l}\text { - En el ítem } 20 \text { Traducir símbolos y metáforas } \\
\text { visuales, históricas, espirituales y emocionales, } \\
\text { sumados a ideas y objetos interpersonalmente } \\
\text { relevantes en sus obras de arte. } \\
\text { - En el ítem 21. Quitaría el (...) } \\
\text { - En el ítem 23. Cierra paréntesis. }\end{array}$ & $\begin{array}{l}\text { - Eliminar el 22: Interactuar (explorar las } \\
\text { relaciones entre conceptos, texto, imágenes, } \\
\text { materiales y entornos artísticos, de forma } \\
\text { individual y/o con pares a través de temas de } \\
\text { arte). }\end{array}$ \\
\hline \multicolumn{2}{|l|}{ RESPECTO A LA DIMENSIÓN DE SATISFACCIÓN } \\
\hline $\begin{array}{l}\text { - Errores de redacción por falta de claridad en la } \\
\text { redacción o finalidad de la evaluación. }\end{array}$ & $\begin{array}{l}\text { - Ítem número 5: concretar más lo que se busca } \\
\text { obtener en este apartado. }\end{array}$ \\
\hline
\end{tabular}

- Apps para educación artística en ESO: aproximadamente 176.000 resultados.

- Apps para el desarrollo de la creatividad: aproximadamente 648.000 resultados.

- Apps para desarrollar el espíritu emprendedor: aproximadamente 254.000 resultados.

Finalmente se añade el término gratuito para centrar en foco de interés ya que se destinará a la educación pública.

- Apps gratuitas para fomentar la creatividad: aproximadamente 281.000 resultados.

- Apps gratuitas para Educación Plástica y Visual: aproximadamente 26.900 resultados. 
Tras estas búsquedas se acota la muestra a una serie de Apps que cumplen todos los criterios establecidos (Educativa, Artística, gratuita, destinada a la etapa de ESO y para sistema operativo Android), pero que además profundizan en los contenidos procedimentales de la ESO, obteniéndose los resultados que se muestran en la tabla 3. Esta muestra es el resultado de la discriminación en base a criterios realizada por el alumnado.

Tabla 3. Volcado de Apps tras los sondeos de los alumnos. Fuente: Elaboración propia.

\begin{tabular}{ll}
\hline APPS PARA AUMENTAR LA CREATIVIDAD & DRAW AND PAINT/PAINT COMMANDER (FREE DRAWING)/ \\
& PICASSO/DRAW, PAINT, DOODLE!/ART OF DRAW \& PAINT/ \\
& YOU PAINT \\
\hline APPS PARA EDITAR FOTOS & PHOTO EDITORPHOTO EDITOR /SELFIES EFFECTS/ \\
& PHOTORUS/ PHOTO COLLAGE EDITOR/ FILTERGRID/ PHOTO \\
& EDITOR/ PICSART ESTUDIO DE FOTOGRAFÍA/ MAGISTO: \\
& VIDEOEDITOR MÁGICO/ VIDTRIM / VIDEO TRIMMER/ \\
& POWERDIRECTOR VIDEO EDITOR/ ANDROVID \\
\hline APPS PARA CREAR CÓMIC & HALFTONE/CREATE A COMIC/COMIC STRIP MAKER \\
\hline APPS & EDMODO/WRITEFULL/MYHOMEWORK/BUSUU/TANGRAM/ \\
EDUCATIVAS & PREGUNTADOS/WATTPAD/APALABRADOS/4 FOTOS 1/SONG \\
& POP/PIANO TILESESTA /QUESTIONS PAU/DUOLINGO/REAL \\
& ACADEMIAESPAÑOLA/MATEMÁTICAS PRÁCTICAS/QUIZUP/ \\
& ATRIVIATE/ADIVINADOS/MINDNODE/EL CUERPO HUMANO/ \\
& MINDOM \\
\hline INSTASHOT / MAGISTO/ PICCOLLAGE/POSING UPP \\
(FOTOGRAFIA)/APP PARA COMO AUMENTAR LA \\
CREATIVIDAD (CONSULTA)/LA VISUALIZACION CREATIVA/ \\
SIMPLEMIND FREE FOR ANDROID (PRODUCTIVA)/RIBOW \\
IDEA/ RORYS STORYCUBES/WORD/SWAG/UNSTUCK/ \\
MINDCANVAS/FLIPBOARD/HYPERLAPSE/MUSIC MAKER \\
JAM: AUTODESK SKETCHBOOK/PICSART ESTUDIO DE \\
FOTOGRAFÍA/PHOTO GRID - COLLAGE MAKER/MEME \\
GENERATOR FREE/LIBROS GRATUITOS - WATTPAD/VIDEOFX \\
MUSIC VIDEO MAKER/BOCETO/TUMBLR/THOUGHTBACK/ \\
IGEOTRAK/3OHANDS/ILUVDRAWING:/6 THIKING HATS/ \\
CREATE-O-MAT \\
\hline
\end{tabular}

Cada una de estas Apps posteriormente fue analizada y documentada para proceder a una selección de las más completas y adecuadas para esta investigación. Tras este análisis y filtrado la muestra final a evaluar con la herramienta se compone de 18 Apps: (AP1)Potery, (AJC2)Juegos Mentales, (A3B3)3D Bones, (ADD4)Draw Dogs, (AFS5)Fashion Studio, (ACG6)Cute Girl, (AFP7)Fantasy Photo Editor, (AI8) Instasize, (AF9)Flipagram, (APC10)Pic Collage, (ALD11)Learn to Draw, (ACC12) Candy camera, (ASL13)Sopa de Letras, (ACP14)Cut Phaste Photos, (AD15)Draw, (APA16)Pics Art, (AP17)Pixton, (ASM18)Stop Motion. 
Diseño de una herramienta de evaluación de apps... - C. Gómez, A. Rico y O. Fontal

\section{RESULTADOS}

La herramienta de evaluación fue distribuida al alumnado evaluador. Cada alumno evaluó las 18 Apps que componen la muestra. Los resultados obtenidos de la evaluación se han sintetizado para este trabajo haciendo media aritmética de las respuestas dadas en cada ítem y traduciéndolos al resultado aproximado. En este trabajo se ha pretendido hacer una evaluación centrada en aspectos cualitativos extraíbles de unos datos estadísticos descriptivos y se reserva para ulteriores estudios el análisis de validación del instrumento, así como su aplicación a muestras mayores y con agentes evaluadores distintos.

De las Apps analizadas y evaluadas se concluye que solamente una de ellas cumple los estándares definidos en todas las dimensiones. Las que más se aproximan a ellos son las señaladas en las dos primeras columnas de la tabla 4.

Tabla 4. Síntesis de resultados. Cumplimiento de estándares. Fuente: Elaboración Propia

\begin{tabular}{|c|c|c|c|c|}
\hline $\begin{array}{c}\text { CUMPLEN } 5 \\
\text { DIMENSIONES }\end{array}$ & $\begin{array}{c}\text { CUMPLEN } 4 \\
\text { DIMENSIONES }\end{array}$ & $\begin{array}{c}\text { CUMPLEN } 3 \\
\text { DIMENSIONES }\end{array}$ & $\begin{array}{c}\text { CUMPLEN } 2 \\
\text { DIMENSIONES }\end{array}$ & $\begin{array}{l}\text { CUMPLEN } 1 \\
\text { DIMENSIÓN }\end{array}$ \\
\hline (AP1) Potery & $\begin{array}{l}\text { (AI8) Instasize } \\
\text { (AJC2)Juegos } \\
\text { Mentales } \\
\text { (APC10)Pic Collage } \\
\text { (AF9)Flipagram } \\
\text { (ACC12)Candy } \\
\text { camera } \\
\text { (ASL13)Sopa de } \\
\text { letras } \\
\text { (A3B3)3 D Bones } \\
\text { (APA16)Pics Art } \\
\text { (ASM18)Stop } \\
\text { Motion }\end{array}$ & $\begin{array}{l}\text { (AFP7)Fantasy } \\
\text { (ALD11)Learn To } \\
\text { Draw }\end{array}$ & $\begin{array}{l}\text { (ADD4)Draw Dogs } \\
\text { (AFS5)Fashion } \\
\text { Studio }\end{array}$ & $\begin{array}{l}\text { (ACG6)Cute Girl } \\
\text { (AP17)Pixton }\end{array}$ \\
\hline
\end{tabular}

Como se puede observar, las que más se alejan son las que se ven recogidas en las columnas de la derecha. No obstante, hay varias que se acercan bastante al estándar ideal, al cumplir los criterios en 4 dimensiones. Llama la atención como la App (AP17) Pixton, en la que se había puesto grandes expectativas por su nivel de descargas, finalmente solo cumple una de las dimensiones.

Se procede a continuación a la exposición comparativa de datos de las Apps evaluadas. Se muestran los gráficos de cada dimensión y los resultados obtenidos por cada App en cada uno de los estándares. Los resultados aparecen sintetizados en doble opción SI/NO, si se alcanza el estándar o si no se alcanza. Para una más rápida visualización se ha dado distinta tonalidad a la casilla atendiendo a la dualidad de respuesta. Las casillas en blanco son aquellas en las que no se ha podido evaluar ese ítem. 
Tabla 5. Comparativa de la dimensión Usabilidad. Fuente: Elaboración propia

ACCESO

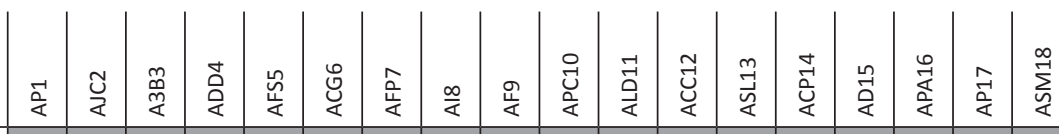

\begin{tabular}{|c|c|c|c|c|c|c|c|c|c|c|c|c|c|c|c|c|c|c|}
\hline & 产 & 岁 & $\stackrel{m}{\dot{c}}$ & 是 & 嵌 & 㢟 & 进 & $\frac{\infty}{\alpha}$ & 㞸 & 高 & 峞 & 㞤 & 育 & 这 & 是 & 产 & 产 & 菦 \\
\hline \multirow{5}{*}{ ACCESO } & 6 & SI & $\mathrm{SI}$ & $\mathrm{SI}$ & $\mathrm{SI}$ & $\mathrm{SI}$ & $\mathrm{SI}$ & $\mathrm{SI}$ & $\mathrm{SI}$ & $\mathrm{SI}$ & $\mathrm{SI}$ & SI & $\mathrm{SI}$ & $\mathrm{SI}$ & SI & $\mathrm{SI}$ & $\mathrm{SI}$ & $\mathrm{SI}$ \\
\hline & $\mathrm{SI}$ & $\mathrm{SI}$ & $\mathrm{SI}$ & $\mathrm{SI}$ & $\mathrm{SI}$ & $\mathrm{SI}$ & $\mathrm{SI}$ & $\mathrm{SI}$ & $\mathrm{SI}$ & $\mathrm{SI}$ & $\mathrm{SI}$ & SI & $\mathrm{SI}$ & SI & SI & $\mathrm{SI}$ & $\mathrm{SI}$ & $\mathrm{SI}$ \\
\hline & $\mathrm{SI}$ & $\mathrm{SI}$ & $\mathrm{SI}$ & SI & $\mathrm{SI}$ & $\mathrm{SI}$ & $\mathrm{SI}$ & $\mathrm{SI}$ & $\mathrm{SI}$ & $\mathrm{SI}$ & $\mathrm{SI}$ & $\mathrm{SI}$ & $\mathrm{SI}$ & $\mathrm{SI}$ & $\mathrm{SI}$ & $\mathrm{SI}$ & $\mathrm{SI}$ & $\mathrm{SI}$ \\
\hline & $\mathrm{SI}$ & $\mathrm{SI}$ & $\mathrm{SI}$ & $\mathrm{SI}$ & $\mathrm{SI}$ & $\mathrm{SI}$ & $\mathrm{SI}$ & $\mathrm{SI}$ & SI & $\mathrm{SI}$ & $\mathrm{SI}$ & $\mathrm{SI}$ & $\mathrm{SI}$ & $\mathrm{SI}$ & $\mathrm{SI}$ & $\mathrm{SI}$ & $\mathrm{SI}$ & $\mathrm{SI}$ \\
\hline & $\mathrm{SI}$ & $\mathrm{SI}$ & $\mathrm{SI}$ & $\mathrm{SI}$ & $\mathrm{SI}$ & $\mathrm{SI}$ & $\mathrm{SI}$ & $\mathrm{SI}$ & SI & $\mathrm{SI}$ & $\mathrm{SI}$ & $\mathrm{SI}$ & $\mathrm{SI}$ & SI & SI & $\mathrm{SI}$ & NO & SI \\
\hline \multirow{11}{*}{ ENLACES } & $\mathrm{SI}$ & $\mathrm{SI}$ & $\mathrm{SI}$ & $\mathrm{SI}$ & $\mathrm{SI}$ & $\mathrm{SI}$ & $\mathrm{SI}$ & $\mathrm{SI}$ & $\mathrm{SI}$ & $\mathrm{SI}$ & NO & $\mathrm{SI}$ & NO & NO & $\mathrm{SI}$ & $\mathrm{SI}$ & $\mathrm{SI}$ & $\mathrm{SI}$ \\
\hline & $\mathrm{SI}$ & $\mathrm{SI}$ & $\mathrm{SI}$ & $\mathrm{SI}$ & NO & $\mathrm{SI}$ & $\mathrm{SI}$ & $\mathrm{SI}$ & $\mathrm{SI}$ & $\mathrm{SI}$ & $\mathrm{SI}$ & $\mathrm{SI}$ & NO & $\mathrm{SI}$ & $\mathrm{SI}$ & NO & NO & $\mathrm{SI}$ \\
\hline & $\mathrm{SI}$ & $\mathrm{SI}$ & $\mathrm{SI}$ & SI & NO & $\mathrm{SI}$ & NO & $\mathrm{SI}$ & $\mathrm{SI}$ & NO & $\mathrm{SI}$ & $\mathrm{SI}$ & NO & $\mathrm{SI}$ & NO & NO & NO & $\mathrm{SI}$ \\
\hline & $\mathrm{SI}$ & NO & $\mathrm{SI}$ & SI & $\mathrm{SI}$ & NO & NO & NO & $\mathrm{SI}$ & NO & $\mathrm{SI}$ & NO & NO & NO & NO & NO & NO & $\mathrm{SI}$ \\
\hline & NO & NO & NO & NO & NO & NO & NO & $\mathrm{SI}$ & NO & NO & NO & NO & NO & NO & NO & NO & NO & NO \\
\hline & $\mathrm{SI}$ & NO & $\mathrm{SI}$ & NO & NO & NO & NO & NO & NO & NO & NO & NO & NO & NO & NO & NO & NO & NO \\
\hline & $\mathrm{SI}$ & $\mathrm{SI}$ & $\mathrm{SI}$ & NO & NO & NO & NO & $\mathrm{SI}$ & NO & NO & NO & NO & NO & NO & NO & $\mathrm{SI}$ & NO & NO \\
\hline & NO & $\mathrm{SI}$ & NO & NO & NO & NO & NO & NO & $\mathrm{SI}$ & NO & NO & NO & NO & NO & No & NO & NO & NO \\
\hline & NO & NO & NO & NO & NO & NO & No & NO & $\mathrm{SI}$ & NO & NO & NO & $\mathrm{SI}$ & NO & No & NO & NO & $\mathrm{SI}$ \\
\hline & & & $\mathrm{SI}$ & $\mathrm{SI}$ & NO & NO & $\mathrm{SI}$ & $\mathrm{SI}$ & NO & NO & NO & NO & NO & NO & $\mathrm{SI}$ & NO & NO & NO \\
\hline & NO & $\mathrm{SI}$ & NO & NO & NO & NO & NO & NO & NO & NO & NO & NO & NO & NO & NO & NO & NO & NO \\
\hline \multirow{2}{*}{ LENGUAJE } & $\mathrm{SI}$ & $\mathrm{SI}$ & $\mathrm{SI}$ & $\mathrm{SI}$ & $\mathrm{SI}$ & NO & $\mathrm{SI}$ & $\mathrm{SI}$ & $\mathrm{SI}$ & $\mathrm{SI}$ & NO & NO & $\mathrm{SI}$ & NO & $\mathrm{SI}$ & NO & NO & $\mathrm{SI}$ \\
\hline & $\mathrm{SI}$ & $\mathrm{SI}$ & $\mathrm{SI}$ & $\mathrm{SI}$ & NO & NO & No & $\mathrm{SI}$ & NO & $\mathrm{SI}$ & & NO & $\mathrm{SI}$ & NO & NO & $\mathrm{SI}$ & NO & NO \\
\hline \multirow{2}{*}{ MEMORIABILIDAD } & & $\mathrm{SI}$ & $\mathrm{SI}$ & $\mathrm{SI}$ & $\mathrm{SI}$ & $\mathrm{SI}$ & NO & $\mathrm{SI}$ & $\mathrm{SI}$ & $\mathrm{SI}$ & $\mathrm{SI}$ & $\mathrm{SI}$ & $\mathrm{SI}$ & $\mathrm{SI}$ & NO & $\mathrm{SI}$ & $\mathrm{SI}$ & $\mathrm{SI}$ \\
\hline & $\mathrm{SI}$ & $\mathrm{SI}$ & $\mathrm{SI}$ & $\mathrm{SI}$ & NO & $\mathrm{SI}$ & $\mathrm{SI}$ & $\mathrm{SI}$ & $\mathrm{SI}$ & $\mathrm{SI}$ & $\mathrm{SI}$ & $\mathrm{SI}$ & NO & NO & $\mathrm{SI}$ & $\mathrm{SI}$ & $\mathrm{SI}$ & $\mathrm{SI}$ \\
\hline \multirow{2}{*}{ CONTENIDO } & $\mathrm{SI}$ & $\mathrm{SI}$ & $\mathrm{SI}$ & $\mathrm{SI}$ & $\mathrm{SI}$ & NO & $\mathrm{SI}$ & $\mathrm{SI}$ & $\mathrm{SI}$ & $\mathrm{SI}$ & $\mathrm{SI}$ & $\mathrm{SI}$ & $\mathrm{SI}$ & NO & NO & $\mathrm{SI}$ & NO & NO \\
\hline & $\mathrm{SI}$ & $\mathrm{SI}$ & $\mathrm{SI}$ & $\mathrm{SI}$ & $\mathrm{SI}$ & $\mathrm{SI}$ & $\mathrm{SI}$ & $\mathrm{SI}$ & $\mathrm{SI}$ & $\mathrm{SI}$ & $\mathrm{SI}$ & $\mathrm{SI}$ & $\mathrm{SI}$ & NO & NO & $\mathrm{SI}$ & $\mathrm{SI}$ & $\mathrm{SI}$ \\
\hline \multirow{2}{*}{ ACCESIBILIDAD } & NO & NO & NO & NO & NO & NO & NO & NO & NO & NO & NO & NO & NO & NO & $\mathrm{SI}$ & NO & NO & NO \\
\hline & $\mathrm{SI}$ & NO & $\mathrm{SI}$ & NO & NO & NO & NO & NO & NO & NO & NO & NO & NO & NO & NO & $\mathrm{SI}$ & NO & NO \\
\hline \multirow{2}{*}{ SEGURIDAD } & No & $\mathrm{SI}$ & NO & $\mathrm{SI}$ & $\mathrm{SI}$ & $\mathrm{SI}$ & $\mathrm{SI}$ & $\mathrm{SI}$ & $\mathrm{SI}$ & $\mathrm{SI}$ & $\mathrm{SI}$ & $\mathrm{SI}$ & $\mathrm{SI}$ & NO & No & $\mathrm{SI}$ & $\mathrm{SI}$ & $\mathrm{SI}$ \\
\hline & $\mathrm{SI}$ & $\mathrm{SI}$ & $\mathrm{SI}$ & NO & NO & NO & NO & $\mathrm{SI}$ & $\mathrm{SI}$ & NO & $\mathrm{SI}$ & $\mathrm{SI}$ & $\mathrm{SI}$ & NO & NO & NO & $\mathrm{SI}$ & $\mathrm{SI}$ \\
\hline PORTABILIDAD & $\mathrm{SI}$ & $\mathrm{SI}$ & NO & $\mathrm{SI}$ & $\mathrm{SI}$ & $\mathrm{SI}$ & $\mathrm{SI}$ & $\mathrm{SI}$ & $\mathrm{SI}$ & $\mathrm{SI}$ & $\mathrm{SI}$ & $\mathrm{SI}$ & $\mathrm{SI}$ & $\mathrm{SI}$ & $\mathrm{SI}$ & $\mathrm{SI}$ & $\mathrm{SI}$ & $\mathrm{SI}$ \\
\hline \multirow{2}{*}{ CONTEXTO } & $\mathrm{SI}$ & $\mathrm{SI}$ & $\mathrm{SI}$ & $\mathrm{SI}$ & $\mathrm{SI}$ & $\mathrm{SI}$ & $\mathrm{SI}$ & $\mathrm{SI}$ & $\mathrm{SI}$ & $\mathrm{SI}$ & $\mathrm{SI}$ & $\mathrm{SI}$ & $\mathrm{SI}$ & $\mathrm{SI}$ & $\mathrm{SI}$ & $\mathrm{SI}$ & $\mathrm{SI}$ & $\mathrm{SI}$ \\
\hline & $\mathrm{SI}$ & $\mathrm{SI}$ & $\mathrm{SI}$ & $\mathrm{SI}$ & $\mathrm{SI}$ & $\mathrm{SI}$ & $\mathrm{SI}$ & $\mathrm{SI}$ & SI & $\mathrm{SI}$ & $\mathrm{SI}$ & $\mathrm{SI}$ & $\mathrm{SI}$ & SI & $\mathrm{SI}$ & $\mathrm{SI}$ & $\mathrm{SI}$ & $\mathrm{SI}$ \\
\hline \multirow{4}{*}{ IMAGENES } & & $\mathrm{SI}$ & $\mathrm{SI}$ & $\mathrm{SI}$ & $\mathrm{SI}$ & NO & $\mathrm{SI}$ & NO & NO & $\mathrm{SI}$ & NO & $\mathrm{SI}$ & $\mathrm{SI}$ & NO & NO & $\mathrm{SI}$ & NO & NO \\
\hline & $\mathrm{SI}$ & $\mathrm{SI}$ & $\mathrm{SI}$ & $\mathrm{SI}$ & $\mathrm{SI}$ & $\mathrm{SI}$ & $\mathrm{SI}$ & $\mathrm{SI}$ & $\mathrm{SI}$ & $\mathrm{SI}$ & $\mathrm{SI}$ & $\mathrm{SI}$ & $\mathrm{SI}$ & NO & SI & $\mathrm{SI}$ & $\mathrm{SI}$ & $\mathrm{SI}$ \\
\hline & $\mathrm{SI}$ & $\mathrm{SI}$ & $\mathrm{SI}$ & NO & $\mathrm{SI}$ & NO & $\mathrm{SI}$ & $\mathrm{SI}$ & $\mathrm{SI}$ & NO & $\mathrm{SI}$ & $\mathrm{SI}$ & $\mathrm{SI}$ & NO & $\mathrm{SI}$ & $\mathrm{SI}$ & $\mathrm{SI}$ & $\mathrm{SI}$ \\
\hline & $\mathrm{SI}$ & $\mathrm{SI}$ & $\mathrm{SI}$ & $\mathrm{SI}$ & NO & NO & NO & NO & NO & $\mathrm{SI}$ & & NO & NO & NO & NO & NO & NO & NO \\
\hline \multirow{2}{*}{ INTERFAZ } & $\mathrm{SI}$ & $\mathrm{SI}$ & NO & $\mathrm{SI}$ & $\mathrm{SI}$ & $\mathrm{SI}$ & $\mathrm{SI}$ & $\mathrm{SI}$ & $\mathrm{SI}$ & $\mathrm{SI}$ & $\mathrm{SI}$ & $\mathrm{SI}$ & $\mathrm{SI}$ & $\mathrm{SI}$ & $\mathrm{SI}$ & $\mathrm{SI}$ & $\mathrm{SI}$ & $\mathrm{SI}$ \\
\hline & SI & SI & NO & SI & SI & NO & SI & SI & SI & SI & $\mathrm{SI}$ & NO & SI & NO & SI & SI & SI & SI \\
\hline
\end{tabular}

Respecto a la usabilidad se puede observar como la mayoría de las Apps cumplen los criterios de acceso. Todas son gratuitas, en un principio y se descargan rápidamente. Mantienen un formato estándar que puede ser leído por cualquier navegador. En definitiva, el criterio de acceso es positivo en todas.

Respecto a la vigencia de enlaces resulta positivo en casi todas las Apps excepto en tres, tal como se puede observar en la tabla. Sin embargo, cuando se habla de enlaces a los sitios de patrocinadores, no hay un predominio de cumplimiento. Sí se 
Diseño de una herramienta de evaluación de apps... - C. Gómez, A. Rico y O. Fontal

puede observar que casi ninguna de las Apss incluye enlaces a los datos originales. Otro dato que resulta llamativo es que casi ninguna App contiene enlaces que retornen a la pantalla principal. Tampoco indican claramente que se está abandonando la App cuando hay enlaces a servidores externos. Esto puede ser debido a que, posiblemente, algunos de estos criterios ya no se ajusten al entorno App, o que no se den opciones para ampliar informaciones. Solamente incluyen motor interno de búsqueda tres Apps. Se manifiesta en el gráfico que solo tres Apps conducen a enlaces de interés. Queda manifiesto también una carencia de mapas de contenidos, índices o tablas de contenidos en la mayoría. Es notoria una carencia de organización jerárquica. En el

Tabla 6. Comparativa de la dimensión Adecuación al contenido. Fuente: Elaboración propia

\begin{tabular}{|c|c|c|c|c|c|c|c|c|c|c|c|c|c|c|c|c|c|c|}
\hline & $\stackrel{-1}{\frac{a}{4}}$ & ঠે & 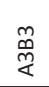 & 薟 & 亗 & 导 & 享 & $\frac{\infty}{<}$ & 昰 & 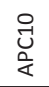 & $\begin{array}{l}\overrightarrow{7} \\
\stackrel{\vec{\alpha}}{\rightleftarrows}\end{array}$ & પ્తુ & $\underset{\stackrel{m}{ت}}{\stackrel{m}{4}}$ & $\begin{array}{l}\vec{J} \\
\stackrel{\Delta}{4}\end{array}$ & $\stackrel{\text { nै }}{\text { 安 }}$ & $\begin{array}{l}0 \\
\stackrel{1}{⿺} \\
\frac{1}{<}\end{array}$ & $\overrightarrow{\hat{Q}}$ & $\sum_{\text {i⿱亠乂 }}^{\infty}$ \\
\hline \multirow{2}{*}{ ACTUALIZACIÓN } & NO & NO & NO & $\mathrm{SI}$ & $\mathrm{SI}$ & $\mathrm{SI}$ & SI & NO & SI & $\mathrm{SI}$ & NO & NO & $\mathrm{SI}$ & SI & NO & NO & SI & SI \\
\hline & $\mathrm{SI}$ & SI & SI & $\mathrm{SI}$ & NO & $\mathrm{SI}$ & SI & SI & SI & SI & SI & SI & SI & SI & SI & SI & NO & NO \\
\hline ADECUACIÓN & NO & NO & NO & SI & NO & $\mathrm{SI}$ & SI & NO & SI & NO & SI & NO & SI & SI & $\mathrm{SI}$ & NO & NO & NO \\
\hline \multirow{4}{*}{ DOCUMENTACIÓN } & NO & NO & NO & NO & NO & $\mathrm{SI}$ & SI & SI & SI & SI & NO & SI & NO & SI & $\mathrm{SI}$ & SI & NO & NO \\
\hline & $\mathrm{SI}$ & SI & $\mathrm{SI}$ & NO & NO & NO & NO & $\mathrm{SI}$ & $\mathrm{SI}$ & NO & NO & SI & SI & NO & SI & NO & NO & NO \\
\hline & NO & NO & NO & NO & NO & NO & NO & NO & NO & $\mathrm{SI}$ & NO & NO & NO & NO & NO & NO & NO & NO \\
\hline & NO & NO & NO & NO & NO & NO & NO & NO & NO & NO & NO & NO & NO & NO & NO & NO & NO & NO \\
\hline \multirow{7}{*}{ ESTRUCTURA } & $\mathrm{SI}$ & $\mathrm{SI}$ & SI & $\mathrm{SI}$ & NO & NO & NO & NO & NO & $\mathrm{SI}$ & NO & SI & SI & NO & NO & NO & NO & NO \\
\hline & NO & $\mathrm{SI}$ & NO & NO & NO & NO & NO & NO & NO & NO & NO & NO & NO & NO & NO & NO & SI & NO \\
\hline & NO & $\mathrm{SI}$ & NO & No & NO & NO & NO & NO & NO & NO & NO & NO & NO & NO & NO & NO & $\mathrm{SI}$ & NO \\
\hline & $\mathrm{SI}$ & $\mathrm{SI}$ & $\mathrm{SI}$ & $\mathrm{SI}$ & $\mathrm{SI}$ & NO & $\mathrm{SI}$ & $\mathrm{SI}$ & NO & NO & NO & $\mathrm{SI}$ & SI & NO & NO & $\mathrm{SI}$ & SI & NO \\
\hline & $\mathrm{SI}$ & $\mathrm{SI}$ & $\mathrm{SI}$ & $\mathrm{SI}$ & $\mathrm{SI}$ & $\mathrm{SI}$ & SI & $\mathrm{SI}$ & $\mathrm{SI}$ & NO & $\mathrm{SI}$ & $\mathrm{SI}$ & SI & NO & $\mathrm{SI}$ & $\mathrm{SI}$ & NO & NO \\
\hline & $\mathrm{SI}$ & $\mathrm{SI}$ & $\mathrm{SI}$ & NO & $\mathrm{SI}$ & NO & NO & $\mathrm{SI}$ & $\mathrm{SI}$ & $\mathrm{SI}$ & $\mathrm{SI}$ & NO & NO & NO & NO & NO & NO & $\mathrm{SI}$ \\
\hline & NO & NO & NO & NO & NO & $\mathrm{SI}$ & NO & NO & NO & SI & NO & NO & NO & NO & NO & NO & NO & $\mathrm{SI}$ \\
\hline \multirow{6}{*}{ CREDITOS } & $\mathrm{SI}$ & $\mathrm{SI}$ & $\mathrm{SI}$ & $\mathrm{SI}$ & $\mathrm{SI}$ & $\mathrm{SI}$ & $\mathrm{SI}$ & SI & $\mathrm{SI}$ & $\mathrm{SI}$ & $\mathrm{SI}$ & $\mathrm{SI}$ & SI & $\mathrm{SI}$ & $\mathrm{SI}$ & $\mathrm{SI}$ & NO & $\mathrm{SI}$ \\
\hline & NO & $\mathrm{SI}$ & NO & $\mathrm{SI}$ & $\mathrm{SI}$ & $\mathrm{SI}$ & SI & NO & $\mathrm{SI}$ & $\mathrm{SI}$ & $\mathrm{SI}$ & $\mathrm{SI}$ & $\mathrm{SI}$ & NO & $\mathrm{SI}$ & $\mathrm{SI}$ & NO & $\mathrm{SI}$ \\
\hline & $\mathrm{SI}$ & $\mathrm{SI}$ & $\mathrm{SI}$ & $\mathrm{SI}$ & NO & $\mathrm{SI}$ & $\mathrm{SI}$ & $\mathrm{SI}$ & $\mathrm{SI}$ & NO & $\mathrm{SI}$ & $\mathrm{SI}$ & $\mathrm{SI}$ & NO & NO & $\mathrm{SI}$ & NO & $\mathrm{SI}$ \\
\hline & $\mathrm{SI}$ & $\mathrm{SI}$ & $\mathrm{SI}$ & $\mathrm{SI}$ & NO & $\mathrm{SI}$ & $\mathrm{SI}$ & $\mathrm{SI}$ & $\mathrm{SI}$ & NO & $\mathrm{SI}$ & $\mathrm{SI}$ & $\mathrm{SI}$ & NO & NO & $\mathrm{SI}$ & NO & NO \\
\hline & $\mathrm{SI}$ & $\mathrm{SI}$ & $\mathrm{SI}$ & $\mathrm{SI}$ & $\mathrm{SI}$ & $\mathrm{SI}$ & $\mathrm{SI}$ & $\mathrm{SI}$ & $\mathrm{SI}$ & NO & $\mathrm{SI}$ & $\mathrm{SI}$ & $\mathrm{SI}$ & & $\mathrm{SI}$ & $\mathrm{SI}$ & NO & $\mathrm{SI}$ \\
\hline & $\mathrm{SI}$ & $\mathrm{SI}$ & $\mathrm{SI}$ & NO & NO & NO & NO & $\mathrm{SI}$ & NO & NO & NO & $\mathrm{SI}$ & $\mathrm{SI}$ & NO & NO & NO & NO & $\mathrm{SI}$ \\
\hline \multirow{6}{*}{$\begin{array}{l}\text { OTROS } \\
\text { ELEMENTOS } \\
\text { TÉCNICOS }\end{array}$} & $\mathrm{SI}$ & $\mathrm{SI}$ & $\mathrm{SI}$ & NO & $\mathrm{SI}$ & NO & NO & NO & NO & NO & NO & NO & NO & NO & NO & NO & NO & $\mathrm{SI}$ \\
\hline & $\mathrm{SI}$ & $\mathrm{SI}$ & $\mathrm{SI}$ & NO & $\mathrm{SI}$ & NO & NO & NO & NO & NO & NO & NO & NO & NO & NO & NO & NO & NO \\
\hline & $\mathrm{SI}$ & $\mathrm{SI}$ & $\mathrm{SI}$ & NO & $\mathrm{SI}$ & NO & NO & NO & NO & NO & NO & NO & NO & NO & NO & NO & NO & $\mathrm{SI}$ \\
\hline & NO & $\mathrm{SI}$ & NO & NO & $\mathrm{SI}$ & NO & NO & NO & NO & NO & NO & NO & NO & NO & NO & NO & NO & $\mathrm{SI}$ \\
\hline & $\mathrm{SI}$ & $\mathrm{SI}$ & $\mathrm{SI}$ & NO & $\mathrm{SI}$ & NO & NO & NO & NO & NO & NO & NO & NO & NO & NO & NO & NO & NO \\
\hline & NO & NO & NO & No & NO & NO & NO & NO & NO & NO & NO & NO & NO & NO & NO & NO & NO & NO \\
\hline \multirow{2}{*}{ FIABILIDAD } & $\mathrm{SI}$ & NO & $\mathrm{SI}$ & NO & NO & NO & NO & & NO & NO & NO & NO & NO & NO & NO & $\mathrm{SI}$ & NO & $\mathrm{SI}$ \\
\hline & NO & NO & NO & NO & NO & NO & NO & NO & $\mathrm{SI}$ & NO & $\mathrm{SI}$ & NO & NO & & NO & NO & NO & NO \\
\hline \multirow{2}{*}{ PUBLICIDAD } & NO & NO & NO & No & NO & NO & NO & NO & $\mathrm{SI}$ & NO & NO & NO & NO & NO & $\mathrm{SI}$ & 9 & SI & NO \\
\hline & $\mathrm{SI}$ & $\mathrm{SI}$ & $\mathrm{SI}$ & $\mathrm{SI}$ & $\mathrm{SI}$ & NO & $\mathrm{SI}$ & $\mathrm{SI}$ & NO & $\mathrm{SI}$ & $\mathrm{SI}$ & No & SI & No & NO & NO & NO & $\mathrm{SI}$ \\
\hline RELEVANCIA & SI & SI & SI & NO & NO & NO & SI & SI & SI & SI & SI & SI & SI & NO & NO & SI & SI & $\mathrm{SI}$ \\
\hline
\end{tabular}


criterio de lenguaje adecuado, tampoco se ve un consenso en un sentido ni en otro. Lo mismo se puede decir respecto al carácter multilingüe.

Se manifiestan en su mayoría positivas en el criterio de memorabilidad y en la no contención de errores. Respecto al criterio de contenido, se considera que la cantidad de palabras por pantalla resulta adecuada en la mayoría de las Apps, así como en lo concerniente a la cantidad de imágenes. Se observa que el criterio de la accesibilidad a la discapacidad no se cumple en casi ninguna (tamaño de letra ajustable, texto alternativo a las imágenes). En general se muestran seguras permitiendo trabajar con normalidad, pero la cantidad de reglas de seguridad, no se muestra positiva en muchas de ellas. Resultan portables la mayoría y todas permiten adaptarse a diferentes contextos. Respecto a las imágenes (equilibrio, color, movimiento) no existe un consenso claro en ningún sentido. En general el diseño de las interfaces y el diseño de menús y botones se valora positivamente.

Atendiendo a la comparativa de la dimensión denominada "Adecuación al contenido", se puede observar como se incumple claramente el criterio documentación (no incluyen guías, no permiten ampliar contenidos con referencias bibliográficas, no hay una hoja de actividades complementarias). Respecto al criterio de estructura solo se muestra positivo el indicador referido a que la organización de los contenidos favorece la transferencia. Casi todas cumplen el criterio de señalar los créditos con claridad.

Hay un gran incumplimiento en el criterio de otros elementos técnicos, quizás debido a que la mayoría de las Apps analizadas carecen de sonidos, animaciones o vídeos. La fiabilidad es un criterio ausente en la mayoría de Apps. Solo tres Apps analizadas no contienen publicidad, aunque es cierto que la mayoría sí permiten el manejo correcto de la App sin que ello suponga molestia. La mayoría de las Apps elegidas se valoran como relevantes dentro de su categoría de contenidos.

Se aprecia que en esta dimensión ninguna de las Apps trabajadas en el aula se adecúa al contenido, lo cual parece sorprendente, sobre todo en el caso de la App (AP17)Pixton que parecía la más concreta y afín a los contenidos de la asignatura "Imagen y Expresión".

La siguiente dimensión que se compara es la referente a las "Metodologías Activas". Empezando con el criterio de actividades, lo que se deduce del análisis es que la mayoría de las actividades que se pueden realizar con las Apps analizadas se manifiestan como motivadoras, además de tener directa relación con los contenidos y objetivos de las asignaturas de Educación Artística de ESO. La mayoría fomenta la creatividad y la exploración. Es clarificadora en la mayoría, la ausencia de mapas de navegación o descripciones de actividades que se pueden realizar. Tampoco se informa de los errores cometidos. Por el contrario, sí se muestra como positivo, curiosamente, que las Apps analizadas permiten aprender de los errores. 
Diseño de una herramienta de evaluación de apps... - C. Gómez, A. Rico y O. Fontal

Tabla 7. Comparativa de la dimensión Metodologías activas. Fuente: Elaboración propia

\begin{tabular}{|c|c|c|c|c|c|c|c|c|c|c|c|c|c|c|c|c|c|c|}
\hline & $\frac{a}{\alpha}$ & $\underset{\mathrm{U}}{\mathrm{U}}$ & 孞 & 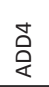 & 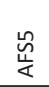 & 过 & 产 & $\frac{\infty}{\varangle}$ & $\underset{\frac{\pi}{4}}{\stackrel{9}{4}}$ & 언 & 㸓 & 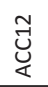 & $\stackrel{m}{\stackrel{m}{ت}}$ & 离 & $\stackrel{\text { n }}{\stackrel{0}{\alpha}}$ & 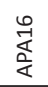 & $\overrightarrow{\hat{\alpha}}$ & $\sum_{\substack{+\infty \\
+\infty}}^{\infty}$ \\
\hline \multirow{14}{*}{ ACTIVIDADES } & $\mathrm{SI}$ & $\mathrm{SI}$ & $\mathrm{SI}$ & $\mathrm{SI}$ & $\mathrm{SI}$ & $\mathrm{SI}$ & $\mathrm{SI}$ & $\mathrm{SI}$ & $\mathrm{SI}$ & $\mathrm{SI}$ & $\mathrm{SI}$ & $\mathrm{SI}$ & $\mathrm{SI}$ & NO & $\mathrm{SI}$ & $\mathrm{SI}$ & $\mathrm{SI}$ & $\mathrm{SI}$ \\
\hline & $\mathrm{SI}$ & $\mathrm{SI}$ & $\mathrm{SI}$ & $\mathrm{SI}$ & $\mathrm{SI}$ & $\mathrm{SI}$ & $\mathrm{SI}$ & $\mathrm{SI}$ & $\mathrm{SI}$ & $\mathrm{SI}$ & $\mathrm{SI}$ & $\mathrm{SI}$ & $\mathrm{SI}$ & $\mathrm{SI}$ & NO & $\mathrm{SI}$ & $\mathrm{SI}$ & $\mathrm{SI}$ \\
\hline & $\mathrm{SI}$ & NO & NO & $\mathrm{SI}$ & $\mathrm{SI}$ & $\mathrm{SI}$ & $\mathrm{SI}$ & $\mathrm{SI}$ & $\mathrm{SI}$ & $\mathrm{SI}$ & $\mathrm{SI}$ & $\mathrm{SI}$ & NO & $\mathrm{SI}$ & $\mathrm{SI}$ & $\mathrm{SI}$ & $\mathrm{SI}$ & $\mathrm{SI}$ \\
\hline & $\mathrm{SI}$ & $\mathrm{SI}$ & $\mathrm{SI}$ & $\mathrm{SI}$ & $\mathrm{SI}$ & $\mathrm{SI}$ & $\mathrm{SI}$ & $\mathrm{SI}$ & $\mathrm{SI}$ & NO & $\mathrm{SI}$ & $\mathrm{SI}$ & $\mathrm{SI}$ & $\mathrm{SI}$ & $\mathrm{SI}$ & $\mathrm{SI}$ & $\mathrm{SI}$ & $\mathrm{SI}$ \\
\hline & $\mathrm{SI}$ & $\mathrm{SI}$ & NO & NO & NO & NO & NO & $\mathrm{SI}$ & $\mathrm{SI}$ & NO & NO & NO & NO & NO & NO & NO & NO & NO \\
\hline & $\mathrm{SI}$ & NO & NO & $\mathrm{SI}$ & NO & $\mathrm{SI}$ & $\mathrm{SI}$ & $\mathrm{SI}$ & $\mathrm{SI}$ & $\mathrm{SI}$ & $\mathrm{SI}$ & $\mathrm{SI}$ & NO & $\mathrm{SI}$ & $\mathrm{SI}$ & $\mathrm{SI}$ & $\mathrm{SI}$ & $\mathrm{SI}$ \\
\hline & $\mathrm{SI}$ & NO & NO & NO & NO & NO & NO & $\mathrm{SI}$ & $\mathrm{SI}$ & NO & $\mathrm{SI}$ & $\mathrm{SI}$ & NO & NO & $\mathrm{SI}$ & $\mathrm{SI}$ & NO & NO \\
\hline & $\mathrm{SI}$ & SI & $\mathrm{SI}$ & NO & SI & $\mathrm{SI}$ & $\mathrm{SI}$ & $\mathrm{SI}$ & $\mathrm{SI}$ & $\mathrm{SI}$ & NO & $\mathrm{SI}$ & $\mathrm{SI}$ & $\mathrm{SI}$ & NO & $\mathrm{SI}$ & NO & SI \\
\hline & NO & NO & $\mathrm{SI}$ & NO & NO & NO & NO & NO & NO & NO & NO & NO & $\mathrm{SI}$ & NO & NO & NO & NO & $\mathrm{NO}$ \\
\hline & $\mathrm{SI}$ & $\mathrm{SI}$ & $\mathrm{SI}$ & $\mathrm{SI}$ & NO & NO & NO & $\mathrm{SI}$ & $\mathrm{SI}$ & NO & $\mathrm{SI}$ & NO & $\mathrm{SI}$ & NO & NO & $\mathrm{SI}$ & NO & $\mathrm{NO}$ \\
\hline & $\mathrm{SI}$ & NO & NO & NO & SI & $\mathrm{SI}$ & NO & $\mathrm{SI}$ & $\mathrm{SI}$ & NO & SI & $\mathrm{SI}$ & $\mathrm{SI}$ & $\mathrm{SI}$ & $\mathrm{SI}$ & $\mathrm{SI}$ & NO & $\mathrm{SI}$ \\
\hline & $\mathrm{SI}$ & NO & NO & NO & NO & NO & NO & $\mathrm{SI}$ & $\mathrm{SI}$ & NO & NO & $\mathrm{SI}$ & NO & NO & NO & $\mathrm{SI}$ & NO & NO \\
\hline & $\mathrm{SI}$ & $\mathrm{SI}$ & $\mathrm{SI}$ & NO & SI & SI & NO & $\mathrm{SI}$ & $\mathrm{SI}$ & NO & SI & $\mathrm{SI}$ & SI & $\mathrm{SI}$ & NO & $\mathrm{SI}$ & $\mathrm{SI}$ & $\mathrm{SI}$ \\
\hline & SI & SI & $\mathrm{SI}$ & NO & NO & NO & $\mathrm{SI}$ & $\mathrm{SI}$ & $\mathrm{SI}$ & NO & SI & $\mathrm{SI}$ & & NO & NO & SI & $\mathrm{SI}$ & $\mathrm{SI}$ \\
\hline \multirow{3}{*}{$\begin{array}{l}\text { CONOCIMIENTOS } \\
\text { PREVIOS }\end{array}$} & NO & & NO & $\mathrm{SI}$ & SI & $\mathrm{SI}$ & SI & $\mathrm{SI}$ & $\mathrm{SI}$ & $\mathrm{SI}$ & No & $\mathrm{SI}$ & SI & $\mathrm{SI}$ & $\mathrm{SI}$ & $\mathrm{SI}$ & $\mathrm{SI}$ & $\mathrm{SI}$ \\
\hline & $\mathrm{SI}$ & $\mathrm{SI}$ & SI & $\mathrm{SI}$ & SI & SI & $\mathrm{SI}$ & $\mathrm{SI}$ & $\mathrm{SI}$ & NO & SI & $\mathrm{SI}$ & SI & SI & $\mathrm{SI}$ & $\mathrm{SI}$ & $\mathrm{SI}$ & SI \\
\hline & $\mathrm{SI}$ & $\mathrm{SI}$ & $\mathrm{SI}$ & $\mathrm{SI}$ & NO & SI & $\mathrm{SI}$ & $\mathrm{SI}$ & $\mathrm{SI}$ & NO & SI & $\mathrm{SI}$ & $\mathrm{SI}$ & $\mathrm{SI}$ & $\mathrm{SI}$ & $\mathrm{SI}$ & $\mathrm{SI}$ & SI \\
\hline \multirow{16}{*}{ CLARIDAD } & NO & NO & NO & NO & NO & NO & NO & NO & NO & NO & $\mathrm{SI}$ & NO & $\mathrm{SI}$ & NO & NO & $\mathrm{SI}$ & $\mathrm{SI}$ & NO \\
\hline & NO & NO & NO & NO & NO & NO & NO & NO & NO & NO & NO & NO & NO & NO & NO & NO & NO & NO \\
\hline & NO & NO & NO & NO & NO & NO & NO & NO & NO & NO & NO & NO & NO & NO & NO & $\mathrm{SI}$ & NO & NO \\
\hline & NO & NO & NO & NO & NO & NO & NO & NO & NO & NO & NO & NO & NO & NO & NO & NO & NO & NO \\
\hline & NO & NO & NO & NO & NO & NO & NO & NO & NO & NO & NO & NO & NO & NO & NO & NO & NO & NO \\
\hline & NO & NO & NO & NO & NO & NO & NO & NO & NO & NO & NO & NO & NO & NO & NO & NO & NO & NO \\
\hline & $\mathrm{SI}$ & $\mathrm{SI}$ & $\mathrm{SI}$ & NO & NO & NO & NO & $\mathrm{SI}$ & NO & NO & NO & $\mathrm{SI}$ & No & NO & NO & $\mathrm{SI}$ & NO & NO \\
\hline & NO & NO & NO & NO & NO & NO & NO & NO & NO & NO & NO & NO & NO & NO & NO & No & NO & NO \\
\hline & NO & NO & NO & NO & NO & NO & NO & NO & NO & NO & NO & NO & NO & NO & NO & NO & NO & NO \\
\hline & $\mathrm{SI}$ & $\mathrm{SI}$ & NO & NO & NO & NO & NO & $\mathrm{SI}$ & $\mathrm{SI}$ & NO & NO & NO & $\mathrm{SI}$ & NO & NO & $\mathrm{SI}$ & NO & NO \\
\hline & $\mathrm{SI}$ & NO & NO & $\mathrm{SI}$ & NO & NO & NO & & $\mathrm{SI}$ & NO & NO & NO & $\mathrm{SI}$ & NO & NO & $\mathrm{SI}$ & NO & NO \\
\hline & $\mathrm{SI}$ & $\mathrm{SI}$ & $\mathrm{SI}$ & NO & NO & $\mathrm{SI}$ & NO & $\mathrm{SI}$ & $\mathrm{SI}$ & NO & NO & $\mathrm{SI}$ & $\mathrm{SI}$ & NO & NO & $\mathrm{SI}$ & NO & $\overline{\mathrm{SI}}$ \\
\hline & $\mathrm{SI}$ & $\mathrm{SI}$ & $\mathrm{SI}$ & NO & NO & SI & NO & $\mathrm{SI}$ & $\mathrm{SI}$ & NO & NO & $\mathrm{SI}$ & NO & $\mathrm{SI}$ & NO & $\mathrm{SI}$ & NO & $\mathrm{SI}$ \\
\hline & NO & NO & NO & NO & NO & NO & NO & NO & NO & NO & NO & NO & NO & NO & NO & NO & $\mathrm{SI}$ & $\mathrm{SI}$ \\
\hline & NO & NO & NO & NO & NO & NO & NO & NO & NO & $\mathrm{SI}$ & NO & NO & No & NO & NO & NO & NO & NO \\
\hline & NO & NO & NO & NO & NO & NO & NO & NO & NO & NO & No & NO & NO & NO & NO & No & NO & NO \\
\hline \multirow{2}{*}{ CONTROL } & $\mathrm{SI}$ & $\mathrm{SI}$ & $\mathrm{SI}$ & $\mathrm{SI}$ & SI & SI & $\mathrm{SI}$ & $\mathrm{SI}$ & $\mathrm{SI}$ & $\mathrm{SI}$ & $\mathrm{SI}$ & $\mathrm{SI}$ & $\mathrm{SI}$ & $\mathrm{SI}$ & NO & $\mathrm{SI}$ & NO & $\mathrm{SI}$ \\
\hline & $\mathrm{SI}$ & NO & NO & NO & NO & NO & $\mathrm{SI}$ & $\mathrm{SI}$ & $\mathrm{SI}$ & $\mathrm{SI}$ & NO & $\mathrm{SI}$ & $\mathrm{SI}$ & $\mathrm{SI}$ & NO & $\mathrm{SI}$ & $\mathrm{SI}$ & $\mathrm{SI}$ \\
\hline \multirow{3}{*}{ DESTINATARIOS } & NO & NO & NO & $\mathrm{SI}$ & NO & $\mathrm{SI}$ & $\mathrm{SI}$ & NO & $\mathrm{SI}$ & $\mathrm{SI}$ & $\mathrm{SI}$ & NO & NO & $\mathrm{SI}$ & $\mathrm{SI}$ & $\mathrm{SI}$ & $\mathrm{SI}$ & NO \\
\hline & $\mathrm{SI}$ & $\mathrm{SI}$ & SI & $\mathrm{SI}$ & NO & $\mathrm{SI}$ & $\mathrm{SI}$ & $\mathrm{SI}$ & $\mathrm{SI}$ & $\mathrm{SI}$ & $\mathrm{SI}$ & $\mathrm{SI}$ & $\mathrm{SI}$ & NO & $\mathrm{SI}$ & $\mathrm{SI}$ & $\mathrm{SI}$ & $\mathrm{SI}$ \\
\hline & $\mathrm{SI}$ & $\mathrm{SI}$ & $\mathrm{SI}$ & $\mathrm{SI}$ & NO & SI & $\mathrm{SI}$ & $\mathrm{SI}$ & $\mathrm{SI}$ & $\mathrm{SI}$ & $\mathrm{SI}$ & $\mathrm{SI}$ & $\mathrm{SI}$ & NO & $\mathrm{SI}$ & $\mathrm{SI}$ & $\mathrm{SI}$ & $\mathrm{SI}$ \\
\hline NIVEL DE & NO & SI & NO & $\mathrm{SI}$ & NO & NO & NO & $\mathrm{SI}$ & $\mathrm{SI}$ & NO & NO & $\mathrm{SI}$ & SI & NO & NO & NO & NO & NO \\
\hline DIFICULTAD & & & & & & & & & & & & & & & & & & \\
\hline \multirow{9}{*}{ FLEXIBILIDAD } & NO & NO & NO & NO & NO & NO & NO & NO & $\mathrm{SI}$ & & $\mathrm{SI}$ & NO & NO & $\mathrm{SI}$ & $\mathrm{SI}$ & $\mathrm{SI}$ & NO & NO \\
\hline & $\mathrm{SI}$ & NO & $\mathrm{SI}$ & NO & NO & SI & NO & NO & $\mathrm{SI}$ & NO & SI & NO & $\mathrm{SI}$ & $\mathrm{SI}$ & $\mathrm{SI}$ & $\mathrm{SI}$ & $\mathrm{SI}$ & $\mathrm{SI}$ \\
\hline & NO & NO & NO & NO & NO & SI & $\mathrm{SI}$ & $\mathrm{SI}$ & $\mathrm{SI}$ & $\mathrm{SI}$ & NO & $\mathrm{SI}$ & NO & SI & NO & SI & NO & $\mathrm{SI}$ \\
\hline & NO & NO & NO & NO & NO & $\mathrm{SI}$ & NO & $\mathrm{SI}$ & $\mathrm{SI}$ & NO & NO & $\mathrm{SI}$ & NO & $\mathrm{SI}$ & NO & SI & $\mathrm{SI}$ & $\mathrm{SI}$ \\
\hline & $\mathrm{SI}$ & $\mathrm{SI}$ & SI & $\mathrm{SI}$ & SI & SI & $\mathrm{SI}$ & $\mathrm{SI}$ & $\mathrm{SI}$ & $\mathrm{SI}$ & SI & $\mathrm{SI}$ & No & NO & NO & $\mathrm{SI}$ & $\mathrm{SI}$ & $\mathrm{SI}$ \\
\hline & $\mathrm{SI}$ & $\mathrm{SI}$ & $\mathrm{SI}$ & NO & NO & SI & $\mathrm{SI}$ & $\mathrm{SI}$ & $\mathrm{SI}$ & $\mathrm{SI}$ & SI & $\mathrm{SI}$ & SI & $\mathrm{SI}$ & $\mathrm{SI}$ & $\mathrm{SI}$ & $\mathrm{SI}$ & $\mathrm{SI}$ \\
\hline & $\mathrm{SI}$ & $\mathrm{SI}$ & $\mathrm{SI}$ & NO & NO & & NO & $\mathrm{SI}$ & $\mathrm{SI}$ & $\mathrm{SI}$ & NO & $\mathrm{SI}$ & NO & SI & $\mathrm{SI}$ & $\mathrm{SI}$ & $\mathrm{SI}$ & NO \\
\hline & $\mathrm{SI}$ & $\mathrm{SI}$ & $\mathrm{SI}$ & NO & NO & NO & NO & $\mathrm{SI}$ & NO & NO & NO & NO & NO & NO & NO & SI & $\mathrm{SI}$ & NO \\
\hline & $\mathrm{SI}$ & NO & NO & $\mathrm{SI}$ & NO & SI & $\mathrm{SI}$ & $\mathrm{SI}$ & $\mathrm{SI}$ & $\mathrm{SI}$ & NO & $\mathrm{SI}$ & NO & SI & NO & SI & NO & SI \\
\hline
\end{tabular}


$\underline{\text { Revista de Humanidades, } 39 \text { (2020). p. 61-98. ISSN 1130-5029 }}$

\begin{tabular}{|c|c|c|c|c|c|c|c|c|c|c|c|c|c|c|c|c|c|c|}
\hline & 京 & $\underset{\mathrm{Z}}{\mathrm{Z}}$ & $\underset{\mathscr{m}}{m}$ & 䒘 & 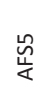 & 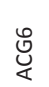 & 军 & $\stackrel{\infty}{\varangle}$ & 戛 & $\begin{array}{l}\text { 엄 } \\
\text { ํㅜㄴ }\end{array}$ & 孚 & 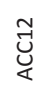 & $\begin{array}{l}\stackrel{n}{ت} \\
\stackrel{ज}{4}\end{array}$ & 离 & $\stackrel{\text { ñ }}{\stackrel{2}{8}}$ & $\begin{array}{l}0 \\
\frac{7}{\alpha} \\
\frac{\alpha}{\alpha}\end{array}$ & 术 & $\sum_{i=1}^{\infty}$ \\
\hline \multirow{10}{*}{ INTERACTIVIDAD } & NO & NO & NO & SI & NO & $\mathrm{SI}$ & NO & SI & $\mathrm{SI}$ & SI & NO & SI & NO & $\mathrm{SI}$ & NO & SI & NO & SI \\
\hline & NO & NO & NO & $\mathrm{SI}$ & NO & NO & NO & $\mathrm{SI}$ & $\mathrm{SI}$ & NO & NO & NO & NO & NO & NO & $\mathrm{SI}$ & NO & NO \\
\hline & NO & NO & NO & NO & NO & NO & NO & $\mathrm{SI}$ & $\mathrm{SI}$ & $\mathrm{SI}$ & NO & SI & NO & NO & NO & $\mathrm{SI}$ & NO & NO \\
\hline & $\mathrm{SI}$ & NO & SI & NO & $\mathrm{SI}$ & $\mathrm{SI}$ & $\mathrm{SI}$ & $\mathrm{SI}$ & $\mathrm{SI}$ & $\mathrm{SI}$ & NO & $\mathrm{SI}$ & NO & $\mathrm{SI}$ & $\mathrm{SI}$ & SI & $\mathrm{SI}$ & $\mathrm{SI}$ \\
\hline & $\mathrm{SI}$ & NO & $\mathrm{SI}$ & NO & NO & NO & NO & $\mathrm{SI}$ & $\mathrm{SI}$ & $\mathrm{SI}$ & NO & $\mathrm{SI}$ & NO & NO & NO & $\mathrm{SI}$ & $\mathrm{SI}$ & $\mathrm{SI}$ \\
\hline & NO & NO & NO & NO & NO & $\mathrm{SI}$ & $\mathrm{SI}$ & $\mathrm{SI}$ & $\mathrm{SI}$ & $\mathrm{SI}$ & NO & NO & NO & NO & NO & $\mathrm{SI}$ & $\mathrm{SI}$ & $\mathrm{SI}$ \\
\hline & $\mathrm{SI}$ & $\mathrm{SI}$ & $\mathrm{SI}$ & $\mathrm{SI}$ & $\mathrm{SI}$ & $\mathrm{SI}$ & $\mathrm{SI}$ & $\mathrm{SI}$ & $\mathrm{SI}$ & $\mathrm{SI}$ & $\mathrm{SI}$ & $\mathrm{SI}$ & NO & $\mathrm{SI}$ & SI & $\mathrm{SI}$ & $\mathrm{SI}$ & $\mathrm{SI}$ \\
\hline & $\mathrm{SI}$ & NO & NO & NO & NO & $\mathrm{SI}$ & $\mathrm{SI}$ & $\mathrm{SI}$ & $\mathrm{SI}$ & $\mathrm{SI}$ & NO & $\mathrm{SI}$ & NO & $\mathrm{SI}$ & NO & $\mathrm{SI}$ & NO & $\mathrm{SI}$ \\
\hline & $\mathrm{SI}$ & NO & SI & $\mathrm{SI}$ & NO & $\mathrm{SI}$ & $\mathrm{SI}$ & $\mathrm{SI}$ & $\mathrm{SI}$ & $\mathrm{SI}$ & SI & $\mathrm{SI}$ & $\mathrm{SI}$ & $\mathrm{SI}$ & $\mathrm{SI}$ & $\mathrm{SI}$ & $\mathrm{SI}$ & $\mathrm{SI}$ \\
\hline & $\mathrm{SI}$ & $\mathrm{SI}$ & SI & NO & $\mathrm{SI}$ & $\mathrm{SI}$ & NO & $\mathrm{SI}$ & $\mathrm{SI}$ & $\mathrm{SI}$ & $\mathrm{SI}$ & $\mathrm{SI}$ & $\mathrm{SI}$ & NO & $\mathrm{SI}$ & $\mathrm{SI}$ & $\mathrm{SI}$ & $\mathrm{SI}$ \\
\hline \multirow{30}{*}{ OBJETIVOS } & $\mathrm{SI}$ & $\mathrm{SI}$ & $\mathrm{SI}$ & $\mathrm{SI}$ & NO & $\mathrm{SI}$ & $\mathrm{SI}$ & $\mathrm{SI}$ & $\mathrm{SI}$ & NO & SI & $\mathrm{SI}$ & $\mathrm{SI}$ & $\mathrm{SI}$ & SI & $\mathrm{SI}$ & $\mathrm{SI}$ & $\mathrm{SI}$ \\
\hline & $\mathrm{SI}$ & $\mathrm{SI}$ & $\mathrm{SI}$ & $\mathrm{SI}$ & NO & NO & $\mathrm{SI}$ & NO & $\mathrm{SI}$ & NO & $\mathrm{SI}$ & & NO & $\mathrm{SI}$ & $\mathrm{SI}$ & $\mathrm{SI}$ & NO & $\mathrm{SI}$ \\
\hline & $\mathrm{SI}$ & $\mathrm{SI}$ & $\mathrm{SI}$ & $\mathrm{SI}$ & NO & NO & $\mathrm{SI}$ & NO & $\mathrm{SI}$ & NO & $\mathrm{SI}$ & $\mathrm{SI}$ & $\mathrm{SI}$ & NO & $\mathrm{SI}$ & $\mathrm{SI}$ & $\mathrm{SI}$ & NO \\
\hline & NO & $\mathrm{NO}$ & NO & $\mathrm{SI}$ & NO & NO & $\mathrm{SI}$ & NO & $\mathrm{SI}$ & $\mathrm{NO}$ & $\mathrm{SI}$ & $\mathrm{SI}$ & NO & NO & $\mathrm{SI}$ & $\mathrm{SI}$ & NO & NO \\
\hline & $\mathrm{SI}$ & $\mathrm{SI}$ & $\mathrm{SI}$ & $\mathrm{SI}$ & $\mathrm{NO}$ & $\mathrm{SI}$ & $\mathrm{SI}$ & $\mathrm{SI}$ & $\mathrm{SI}$ & NO & $\mathrm{SI}$ & $\mathrm{SI}$ & $\mathrm{SI}$ & NO & SI & $\mathrm{SI}$ & NO & NO \\
\hline & $\mathrm{SI}$ & $\mathrm{SI}$ & $\mathrm{SI}$ & NO & NO & NO & NO & NO & NO & NO & $\mathrm{SI}$ & NO & SI & NO & NO & NO & NO & NO \\
\hline & $\mathrm{SI}$ & SI & $\mathrm{SI}$ & NO & NO & NO & NO & $\mathrm{SI}$ & $\mathrm{SI}$ & NO & $\mathrm{SI}$ & $\mathrm{SI}$ & NO & NO & NO & $\mathrm{SI}$ & NO & NO \\
\hline & $\mathrm{SI}$ & SI & $\mathrm{SI}$ & $\mathrm{SI}$ & $\mathrm{SI}$ & $\mathrm{SI}$ & $\mathrm{SI}$ & $\mathrm{SI}$ & $\mathrm{SI}$ & $\mathrm{SI}$ & $\mathrm{SI}$ & $\mathrm{SI}$ & NO & $\mathrm{SI}$ & SI & $\mathrm{SI}$ & $\mathrm{SI}$ & $\mathrm{SI}$ \\
\hline & $\mathrm{SI}$ & $\mathrm{SI}$ & NO & $\mathrm{SI}$ & $\mathrm{NO}$ & $\mathrm{SI}$ & $\mathrm{SI}$ & $\mathrm{SI}$ & $\mathrm{SI}$ & $\mathrm{SI}$ & $\mathrm{SI}$ & $\mathrm{SI}$ & $\mathrm{SI}$ & $\mathrm{SI}$ & $\mathrm{SI}$ & $\mathrm{SI}$ & $\mathrm{SI}$ & $\mathrm{SI}$ \\
\hline & $\mathrm{SI}$ & $\mathrm{SI}$ & $\mathrm{SI}$ & $\mathrm{SI}$ & NO & NO & SI & $\mathrm{SI}$ & $\mathrm{SI}$ & $\mathrm{SI}$ & SI & $\mathrm{SI}$ & $\mathrm{SI}$ & NO & SI & SI & NO & $\mathrm{SI}$ \\
\hline & $\mathrm{NO}$ & $\mathrm{NO}$ & $\mathrm{NO}$ & NO & $\mathrm{NO}$ & NO & $\mathrm{NO}$ & $\mathrm{SI}$ & $\mathrm{SI}$ & $\mathrm{SI}$ & NO & $\mathrm{SI}$ & $\mathrm{SI}$ & NO & NO & $\mathrm{SI}$ & NO & NO \\
\hline & $\mathrm{SI}$ & SI & $\mathrm{SI}$ & $\mathrm{SI}$ & $\mathrm{SI}$ & $\mathrm{SI}$ & $\mathrm{SI}$ & $\mathrm{SI}$ & $\mathrm{SI}$ & $\mathrm{SI}$ & $\mathrm{SI}$ & $\mathrm{SI}$ & $\mathrm{SI}$ & $\mathrm{SI}$ & SI & $\mathrm{SI}$ & $\mathrm{SI}$ & $\mathrm{SI}$ \\
\hline & $\mathrm{SI}$ & & $\mathrm{SI}$ & $\mathrm{SI}$ & $\mathrm{SI}$ & $\mathrm{SI}$ & $\mathrm{SI}$ & $\mathrm{SI}$ & $\mathrm{SI}$ & $\mathrm{SI}$ & SI & $\mathrm{SI}$ & NO & $\mathrm{SI}$ & $\mathrm{SI}$ & $\mathrm{SI}$ & $\mathrm{SI}$ & $\mathrm{SI}$ \\
\hline & $\mathrm{SI}$ & $\mathrm{SI}$ & $\mathrm{SI}$ & $\mathrm{SI}$ & $\mathrm{SI}$ & $\mathrm{SI}$ & $\mathrm{SI}$ & $\mathrm{SI}$ & $\mathrm{SI}$ & $\mathrm{SI}$ & $\mathrm{SI}$ & & $\mathrm{SI}$ & $\mathrm{SI}$ & $\mathrm{SI}$ & $\mathrm{SI}$ & $\mathrm{SI}$ & $\mathrm{SI}$ \\
\hline & $\mathrm{SI}$ & SI & $\mathrm{SI}$ & $\mathrm{SI}$ & $\mathrm{SI}$ & $\mathrm{SI}$ & $\mathrm{SI}$ & $\mathrm{SI}$ & $\mathrm{SI}$ & $\mathrm{SI}$ & $\mathrm{SI}$ & $\mathrm{SI}$ & NO & $\mathrm{SI}$ & $\mathrm{SI}$ & $\mathrm{SI}$ & $\mathrm{SI}$ & $\mathrm{SI}$ \\
\hline & $\mathrm{SI}$ & NO & NO & $\mathrm{SI}$ & $\mathrm{SI}$ & $\mathrm{SI}$ & $\mathrm{SI}$ & $\mathrm{SI}$ & $\mathrm{SI}$ & $\mathrm{SI}$ & $\mathrm{SI}$ & $\mathrm{SI}$ & NO & $\mathrm{SI}$ & SI & SI & $\mathrm{SI}$ & $\mathrm{SI}$ \\
\hline & SI & $\mathrm{SI}$ & SI & NO & NO & NO & NO & $\mathrm{SI}$ & $\mathrm{SI}$ & NO & NO & $\mathrm{SI}$ & $\mathrm{SI}$ & NO & NO & $\mathrm{SI}$ & NO & $\mathrm{SI}$ \\
\hline & $\mathrm{SI}$ & $\mathrm{SI}$ & NO & NO & $\mathrm{NO}$ & NO & $\mathrm{SI}$ & $\mathrm{SI}$ & $\mathrm{SI}$ & $\mathrm{SI}$ & NO & $\mathrm{SI}$ & $\mathrm{NO}$ & $\mathrm{SI}$ & $\mathrm{NO}$ & $\mathrm{SI}$ & & $\mathrm{SI}$ \\
\hline & SI & SI & SI & $\mathrm{SI}$ & $\mathrm{SI}$ & $\mathrm{SI}$ & SI & $\mathrm{SI}$ & $\mathrm{SI}$ & $\mathrm{SI}$ & SI & $\mathrm{SI}$ & SI & $\mathrm{SI}$ & SI & SI & $\mathrm{SI}$ & $\mathrm{SI}$ \\
\hline & $\mathrm{SI}$ & NO & NO & $\mathrm{SI}$ & $\mathrm{NO}$ & $\mathrm{SI}$ & $\mathrm{SI}$ & $\mathrm{SI}$ & $\mathrm{SI}$ & $\mathrm{SI}$ & $\mathrm{SI}$ & $\mathrm{SI}$ & $\mathrm{SI}$ & $\mathrm{SI}$ & $\mathrm{SI}$ & SI & $\mathrm{SI}$ & $\mathrm{SI}$ \\
\hline & NO & NO & NO & NO & NO & NO & SI & NO & $\mathrm{SI}$ & $\mathrm{SI}$ & NO & NO & NO & NO & NO & $\mathrm{SI}$ & $\mathrm{SI}$ & $\mathrm{SI}$ \\
\hline & $\mathrm{SI}$ & & NO & NO & $\mathrm{SI}$ & $\mathrm{SI}$ & $\mathrm{SI}$ & $\mathrm{SI}$ & $\mathrm{SI}$ & $\mathrm{SI}$ & $\mathrm{SI}$ & $\mathrm{SI}$ & $\mathrm{NO}$ & $\mathrm{SI}$ & $\mathrm{SI}$ & $\mathrm{SI}$ & $\mathrm{SI}$ & $\mathrm{SI}$ \\
\hline & NO & NO & NO & NO & $\mathrm{NO}$ & NO & $\mathrm{SI}$ & NO & $\mathrm{SI}$ & $\mathrm{SI}$ & NO & NO & NO & NO & NO & $\mathrm{SI}$ & NO & NO \\
\hline & SI & NO & SI & NO & NO & $\mathrm{SI}$ & $\mathrm{SI}$ & $\mathrm{SI}$ & $\mathrm{SI}$ & $\mathrm{SI}$ & NO & $\mathrm{SI}$ & $\mathrm{SI}$ & NO & NO & $\mathrm{SI}$ & $\mathrm{SI}$ & $\mathrm{SI}$ \\
\hline & $\mathrm{SI}$ & No & $\mathrm{SI}$ & NO & NO & NO & $\mathrm{NO}$ & NO & NO & $\mathrm{NO}$ & NO & NO & $\mathrm{NO}$ & NO & NO & NO & NO & NO \\
\hline & $\mathrm{SI}$ & NO & SI & $\mathrm{SI}$ & NO & NO & NO & NO & NO & NO & NO & NO & NO & NO & NO & NO & NO & NO \\
\hline & SI & $\mathrm{SI}$ & $\mathrm{SI}$ & $\mathrm{SI}$ & $\mathrm{SI}$ & $\mathrm{SI}$ & $\mathrm{SI}$ & $\mathrm{SI}$ & $\mathrm{SI}$ & $\mathrm{SI}$ & $\mathrm{SI}$ & $\mathrm{SI}$ & NO & NO & NO & $\mathrm{SI}$ & NO & $\mathrm{SI}$ \\
\hline & $\mathrm{SI}$ & $\mathrm{SI}$ & NO & NO & NO & $\mathrm{SI}$ & $\mathrm{SI}$ & $\mathrm{SI}$ & $\mathrm{SI}$ & $\mathrm{SI}$ & $\mathrm{SI}$ & $\mathrm{SI}$ & $\mathrm{SI}$ & NO & $\mathrm{SI}$ & $\mathrm{SI}$ & $\mathrm{SI}$ & $\mathrm{SI}$ \\
\hline & $\mathrm{SI}$ & $\mathrm{SI}$ & $\mathrm{SI}$ & NO & NO & $\mathrm{SI}$ & $\mathrm{SI}$ & $\mathrm{SI}$ & & $\mathrm{SI}$ & NO & $\mathrm{SI}$ & $\mathrm{SI}$ & NO & $\mathrm{SI}$ & $\mathrm{SI}$ & $\mathrm{SI}$ & $\mathrm{SI}$ \\
\hline & $\mathrm{SI}$ & $\mathrm{SI}$ & $\mathrm{SI}$ & $\mathrm{SI}$ & NO & NO & $\mathrm{SI}$ & $\mathrm{SI}$ & $\mathrm{SI}$ & NO & $\mathrm{SI}$ & $\mathrm{SI}$ & $\mathrm{SI}$ & NO & NO & $\mathrm{SI}$ & $\mathrm{SI}$ & NO \\
\hline \multirow{3}{*}{ GRADO DE } & $\mathrm{SI}$ & $\mathrm{SI}$ & $\mathrm{SI}$ & $\mathrm{SI}$ & $\mathrm{SI}$ & $\mathrm{SI}$ & $\mathrm{SI}$ & & $\mathrm{SI}$ & $\mathrm{SI}$ & NO & $\mathrm{SI}$ & $\mathrm{SI}$ & NO & NO & $\mathrm{SI}$ & $\mathrm{SI}$ & $\mathrm{SI}$ \\
\hline & $\mathrm{SI}$ & $\mathrm{SI}$ & $\mathrm{SI}$ & $\mathrm{SI}$ & $\mathrm{SI}$ & $\mathrm{SI}$ & $\mathrm{SI}$ & $\mathrm{SI}$ & $\mathrm{SI}$ & $\mathrm{SI}$ & SI & $\mathrm{SI}$ & NO & $\mathrm{SI}$ & $\mathrm{SI}$ & $\mathrm{SI}$ & $\mathrm{SI}$ & $\mathrm{SI}$ \\
\hline & $\mathrm{SI}$ & $\mathrm{SI}$ & $\mathrm{SI}$ & $\mathrm{SI}$ & $\mathrm{SI}$ & $\mathrm{SI}$ & $\mathrm{SI}$ & $\mathrm{SI}$ & $\mathrm{SI}$ & $\mathrm{SI}$ & NO & $\mathrm{SI}$ & NO & NO & NO & $\mathrm{SI}$ & NO & $\mathrm{SI}$ \\
\hline \multirow{2}{*}{ VLORES } & NO & NO & NO & NO & NO & NO & NO & NO & NO & $\mathrm{SI}$ & NO & NO & NO & NO & NO & $\mathrm{SI}$ & & NO \\
\hline & NO & NO & NO & NO & NO & NO & NO & NO & NO & NO & $\mathrm{SI}$ & NO & NO & NO & NO & NO & NO & NO \\
\hline \multirow{7}{*}{$\begin{array}{l}\text { ASPECTOS } \\
\text { COGNITIVOS }\end{array}$} & $\mathrm{SI}$ & $\mathrm{SI}$ & $\mathrm{SI}$ & NO & $\mathrm{SI}$ & $\mathrm{SI}$ & $\mathrm{SI}$ & $\mathrm{SI}$ & $\mathrm{SI}$ & $\mathrm{SI}$ & NO & $\mathrm{SI}$ & $\mathrm{SI}$ & NO & $\mathrm{SI}$ & SI & $\mathrm{SI}$ & NO \\
\hline & $\mathrm{SI}$ & $\mathrm{SI}$ & $\mathrm{SI}$ & $\mathrm{SI}$ & $\mathrm{SI}$ & $\mathrm{SI}$ & $\mathrm{SI}$ & $\mathrm{SI}$ & $\mathrm{SI}$ & $\mathrm{SI}$ & $\mathrm{SI}$ & $\mathrm{SI}$ & SI & $\mathrm{SI}$ & $\mathrm{SI}$ & $\mathrm{SI}$ & $\mathrm{SI}$ & $\mathrm{SI}$ \\
\hline & $\mathrm{SI}$ & $\mathrm{SI}$ & $\mathrm{SI}$ & NO & $\mathrm{SI}$ & $\mathrm{SI}$ & NO & $\mathrm{SI}$ & $\mathrm{SI}$ & $\mathrm{SI}$ & $\mathrm{SI}$ & $\mathrm{SI}$ & NO & NO & $\mathrm{SI}$ & $\mathrm{SI}$ & $\mathrm{SI}$ & $\mathrm{SI}$ \\
\hline & $\mathrm{SI}$ & $\mathrm{SI}$ & $\mathrm{SI}$ & NO & $\mathrm{SI}$ & $\mathrm{SI}$ & $\mathrm{SI}$ & $\mathrm{SI}$ & $\mathrm{SI}$ & $\mathrm{SI}$ & NO & NO & $\mathrm{SI}$ & NO & NO & $\mathrm{SI}$ & NO & $\mathrm{SI}$ \\
\hline & $\mathrm{SI}$ & $\mathrm{SI}$ & $\mathrm{SI}$ & NO & $\mathrm{SI}$ & $\mathrm{SI}$ & NO & $\mathrm{SI}$ & $\mathrm{SI}$ & $\mathrm{SI}$ & NO & NO & NO & NO & NO & $\mathrm{SI}$ & NO & $\mathrm{SI}$ \\
\hline & $\mathrm{SI}$ & $\mathrm{SI}$ & $\mathrm{SI}$ & $\mathrm{SI}$ & $\mathrm{SI}$ & $\mathrm{SI}$ & $\mathrm{SI}$ & $\mathrm{SI}$ & $\mathrm{SI}$ & $\mathrm{SI}$ & $\mathrm{SI}$ & $\mathrm{SI}$ & $\mathrm{SI}$ & $\mathrm{SI}$ & $\mathrm{SI}$ & $\mathrm{SI}$ & $\mathrm{SI}$ & $\mathrm{SI}$ \\
\hline & SI & $\mathrm{SI}$ & $\mathrm{SI}$ & $\mathrm{SI}$ & $\mathrm{SI}$ & $\mathrm{SI}$ & SI & $\mathrm{SI}$ & $\mathrm{SI}$ & SI & SI & $\mathrm{SI}$ & $\mathrm{SI}$ & $\mathrm{SI}$ & $\mathrm{SI}$ & $\mathrm{SI}$ & $\mathrm{SI}$ & $\mathrm{SI}$ \\
\hline
\end{tabular}


Diseño de una herramienta de evaluación de apps... - C. Gómez, A. Rico y O. Fontal

Otro aspecto que aparece como positivo es que no son necesarios conocimientos previos para conseguir llegar a resultados. Queda manifiesto que el criterio de claridad de la información, no se cumple en casi ninguno de los indicadores. Esto puede ser debido a que la mayoría de las Apps elegidas tienen un enfoque práctico y no teórico, por lo que resulta ausente más que negativo. Respecto al criterio de control, se puede observar que es posible el manejo de la secuencia de aprendizaje por parte del usuario, pero, sin embargo, no es posible retomar la actividad en el punto donde se ha abandonado. Se adaptan al currículum en su mayoría, aunque no aclaran la audiencia a la que se destinan.

Por lo general no son flexibles, en cuanto a la posibilidad de modificar contenido, aunque sí dejan elegir qué se quiere aprender y en qué orden. Respecto al criterio de interactividad, se valora positivamente el fomento de la actividad individual e instrumental, y que dan posibilidad a realizar actividades de diseño personal. También se muestra positivo el fomento de la participación del alumno.

Respecto al criterio de objetivos y su indicación en la pantalla principal, se puede exponer que es ausente en la mayoría de Apps.

Se puede asegurar que todas excepto una, fomentan el libre descubrimiento. Ello se puede relacionar con la falta de guías e instrucciones que se especificó en la dimensión anterior. Casi todas permiten la función de ejercitar habilidades, instruir, motivar, explorar, entender, experimentar, resolver problemas, crear y expresarse.

Todas fomentan la motivación. Los objetivos fallan en que no se formulan de manera precisa, ni aparecen definidos al inicio de la App. En general ayuda a mantener el grado de atención, aunque, por otro lado, carecen de la potenciación de valores. Para finalizar esta dimensión, se hace mención a los aspectos cognitivos que

Tabla 8. Comparativa de la dimensión Fomento de la Creatividad desde la Educación Artística. Fuente: Elaboración propia

\begin{tabular}{|c|c|c|c|c|c|c|c|c|c|c|c|c|c|c|c|c|c|c|}
\hline & $\overrightarrow{\frac{1}{4}}$ & ত্য & 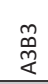 & 苍 & 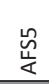 & 导 & 产 & $\frac{\infty}{4}$ & 范 & 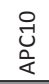 & $\overrightarrow{\vec{\theta}}$ & ت્ّ & $\frac{m}{\vec{u}}$ & 离 & $\stackrel{\text { ñ }}{\frac{\alpha}{\alpha}}$ & $\begin{array}{l}0 \\
\frac{1}{\alpha} \\
\frac{\alpha}{\alpha}\end{array}$ & 定 & $\sum_{\substack{\alpha \\
<}}^{\infty}$ \\
\hline \multirow{12}{*}{ CONSTRUIR } & SI & $\mathrm{SI}$ & NO & $\mathrm{SI}$ & $\mathrm{SI}$ & $\mathrm{SI}$ & $\mathrm{SI}$ & SI & $\mathrm{SI}$ & $\mathrm{SI}$ & $\mathrm{SI}$ & $\mathrm{SI}$ & NO & $\mathrm{SI}$ & $\mathrm{SI}$ & $\mathrm{SI}$ & $\mathrm{SI}$ & SI \\
\hline & SI & SI & NO & SI & $\mathrm{SI}$ & $\mathrm{SI}$ & NO & SI & $\mathrm{SI}$ & $\mathrm{SI}$ & $\mathrm{SI}$ & $\mathrm{SI}$ & NO & NO & NO & $\mathrm{SI}$ & $\mathrm{SI}$ & NO \\
\hline & NO & NO & $\mathrm{NO}$ & NO & NO & NO & NO & $\mathrm{SI}$ & $\mathrm{SI}$ & & $\mathrm{NO}$ & NO & NO & NO & $\mathrm{NO}$ & $\mathrm{NO}$ & NO & \\
\hline & $\mathrm{SI}$ & NO & NO & NO & NO & $\mathrm{SI}$ & $\mathrm{SI}$ & $\mathrm{SI}$ & SI & $\mathrm{SI}$ & NO & $\mathrm{SI}$ & NO & $\mathrm{SI}$ & NO & $\mathrm{SI}$ & NO & SI \\
\hline & $\mathrm{SI}$ & NO & NO & NO & $\mathrm{SI}$ & $\mathrm{SI}$ & NO & $\mathrm{SI}$ & $\mathrm{SI}$ & $\mathrm{SI}$ & $\mathrm{SI}$ & $\mathrm{SI}$ & $\mathrm{NO}$ & $\mathrm{SI}$ & $\mathrm{NO}$ & $\mathrm{SI}$ & $\mathrm{SI}$ & $\mathrm{SI}$ \\
\hline & NO & NO & NO & $\mathrm{SI}$ & $\mathrm{SI}$ & $\mathrm{SI}$ & $\mathrm{SI}$ & $\mathrm{SI}$ & $\mathrm{SI}$ & $\mathrm{SI}$ & $\mathrm{SI}$ & $\mathrm{SI}$ & NO & NO & NO & $\mathrm{SI}$ & $\mathrm{SI}$ & SI \\
\hline & $\mathrm{SI}$ & NO & NO & NO & NO & $\mathrm{SI}$ & NO & $\mathrm{SI}$ & $\mathrm{SI}$ & NO & NO & $\mathrm{SI}$ & $\mathrm{NO}$ & $\mathrm{NO}$ & NO & $\mathrm{SI}$ & $\mathrm{NO}$ & $\mathrm{SI}$ \\
\hline & NO & NO & NO & NO & NO & NO & NO & $\mathrm{SI}$ & $\mathrm{SI}$ & NO & NO & $\mathrm{SI}$ & NO & NO & NO & $\mathrm{SI}$ & NO & $\mathrm{SI}$ \\
\hline & $\mathrm{SI}$ & NO & $\mathrm{SI}$ & NO & NO & NO & NO & $\mathrm{SI}$ & $\mathrm{SI}$ & NO & NO & $\mathrm{SI}$ & $\mathrm{SI}$ & NO & NO & $\mathrm{SI}$ & NO & NO \\
\hline & $\mathrm{SI}$ & $\mathrm{SI}$ & $\mathrm{SI}$ & NO & $\mathrm{SI}$ & $\mathrm{SI}$ & $\mathrm{SI}$ & $\mathrm{SI}$ & $\mathrm{SI}$ & $\mathrm{SI}$ & $\mathrm{NO}$ & $\mathrm{SI}$ & $\mathrm{SI}$ & NO & $\mathrm{NO}$ & $\mathrm{SI}$ & NO & $\mathrm{SI}$ \\
\hline & NO & NO & NO & NO & $\mathrm{SI}$ & $\mathrm{SI}$ & NO & $\mathrm{SI}$ & $\mathrm{SI}$ & $\mathrm{SI}$ & NO & $\mathrm{SI}$ & NO & NO & NO & NO & $\mathrm{SI}$ & $\mathrm{SI}$ \\
\hline & NO & NO & NO & NO & NO & NO & NO & NO & SI & NO & NO & NO & NO & NO & NO & NO & $\mathrm{SI}$ & NO \\
\hline
\end{tabular}


$\underline{\text { Revista de Humanidades, } 39 \text { (2020). p. 61-98. ISSN 1130-5029 }}$

\begin{tabular}{|c|c|c|c|c|c|c|c|c|c|c|c|c|c|c|c|c|c|c|}
\hline & 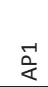 & $\underset{\mathrm{U}}{\mathrm{Z}}$ & $\underset{\substack{m \\
\dot{m}}}{m}$ & 茖 & 岂 & 过 & $\hat{\frac{\hat{\alpha}}{4}}$ & $\frac{\infty}{\varangle}$ & 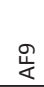 & 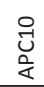 & 孚 & 艺 & $\stackrel{m}{\stackrel{n}{4}}$ & 売 & $\stackrel{\text { ñ }}{\stackrel{2}{\leftarrow}}$ & $\frac{0}{\frac{1}{a}}$ & 妾 & $\sum_{\substack{\infty \\
\leftarrow}}^{\infty}$ \\
\hline \multirow{15}{*}{ APLICAR } & $\mathrm{SI}$ & $\mathrm{SI}$ & NO & $\mathrm{SI}$ & $\mathrm{SI}$ & $\mathrm{SI}$ & $\mathrm{SI}$ & $\mathrm{SI}$ & $\mathrm{SI}$ & $\mathrm{SI}$ & $\mathrm{SI}$ & $\mathrm{SI}$ & $\mathrm{NO}$ & $\mathrm{SI}$ & $\mathrm{SI}$ & $\mathrm{SI}$ & $\mathrm{SI}$ & $\mathrm{SI}$ \\
\hline & $\mathrm{SI}$ & $\mathrm{NO}$ & $\mathrm{NO}$ & $\mathrm{SI}$ & $\mathrm{NO}$ & $\mathrm{SI}$ & $\mathrm{SI}$ & $\mathrm{SI}$ & $\mathrm{SI}$ & $\mathrm{SI}$ & $\mathrm{SI}$ & $\mathrm{SI}$ & $\mathrm{NO}$ & $\mathrm{SI}$ & $\mathrm{SI}$ & $\mathrm{SI}$ & $\mathrm{SI}$ & $\mathrm{SI}$ \\
\hline & $\mathrm{SI}$ & NO & NO & $\mathrm{NO}$ & $\mathrm{SI}$ & NO & $\mathrm{SI}$ & $\mathrm{SI}$ & $\mathrm{SI}$ & $\mathrm{SI}$ & $\mathrm{SI}$ & $\mathrm{SI}$ & NO & $\mathrm{SI}$ & $\mathrm{SI}$ & $\mathrm{SI}$ & $\mathrm{SI}$ & $\mathrm{SI}$ \\
\hline & $\mathrm{SI}$ & NO & $\mathrm{NO}$ & $\mathrm{NO}$ & NO & NO & $\mathrm{SI}$ & $\mathrm{SI}$ & $\mathrm{SI}$ & $\mathrm{SI}$ & $\mathrm{SI}$ & $\mathrm{SI}$ & $\mathrm{NO}$ & $\mathrm{SI}$ & $\mathrm{SI}$ & $\mathrm{SI}$ & $\mathrm{SI}$ & $\mathrm{SI}$ \\
\hline & $\mathrm{SI}$ & NO & NO & NO & $\mathrm{SI}$ & NO & NO & NO & NO & NO & NO & NO & NO & NO & NO & NO & NO & $\mathrm{NO}$ \\
\hline & $\mathrm{SI}$ & NO & NO & NO & NO & NO & NO & $\mathrm{SI}$ & & NO & $\mathrm{SI}$ & $\mathrm{SI}$ & $\mathrm{NO}$ & $\mathrm{SI}$ & NO & $\mathrm{SI}$ & $\mathrm{SI}$ & $\mathrm{SI}$ \\
\hline & NO & NO & NO & NO & NO & NO & $\mathrm{SI}$ & $\mathrm{SI}$ & $\mathrm{SI}$ & NO & NO & $\mathrm{SI}$ & NO & $\mathrm{SI}$ & NO & NO & $\mathrm{SI}$ & $\mathrm{NO}$ \\
\hline & NO & $\mathrm{NO}$ & $\mathrm{NO}$ & NO & NO & NO & NO & NO & $\mathrm{SI}$ & NO & NO & NO & $\mathrm{NO}$ & NO & $\mathrm{NO}$ & $\mathrm{NO}$ & NO & $\mathrm{NO}$ \\
\hline & $\mathrm{SI}$ & NO & $\mathrm{NO}$ & NO & $\mathrm{NO}$ & $\mathrm{SI}$ & $\mathrm{SI}$ & $\mathrm{SI}$ & $\mathrm{SI}$ & NO & NO & $\mathrm{SI}$ & $\mathrm{NO}$ & NO & $\mathrm{SI}$ & $\mathrm{SI}$ & NO & $\mathrm{SI}$ \\
\hline & $\mathrm{SI}$ & NO & $\mathrm{SI}$ & NO & NO & $\mathrm{SI}$ & $\mathrm{SI}$ & $\mathrm{SI}$ & $\mathrm{SI}$ & NO & NO & $\mathrm{SI}$ & NO & NO & NO & $\mathrm{SI}$ & NO & $\mathrm{SI}$ \\
\hline & NO & NO & $\mathrm{NO}$ & NO & NO & NO & $\mathrm{SI}$ & NO & $\mathrm{SI}$ & $\mathrm{SI}$ & NO & $\mathrm{SI}$ & $\mathrm{NO}$ & NO & NO & $\mathrm{SI}$ & NO & $\mathrm{SI}$ \\
\hline & NO & NO & NO & $\mathrm{SI}$ & NO & $\mathrm{NO}$ & NO & $\mathrm{SI}$ & $\mathrm{SI}$ & $\mathrm{SI}$ & NO & $\mathrm{SI}$ & NO & NO & $\mathrm{SI}$ & $\mathrm{SI}$ & NO & $\mathrm{SI}$ \\
\hline & NO & NO & NO & NO & NO & $\mathrm{SI}$ & $\mathrm{SI}$ & $\mathrm{SI}$ & $\mathrm{SI}$ & $\mathrm{SI}$ & NO & $\mathrm{SI}$ & NO & $\mathrm{SI}$ & NO & $\mathrm{SI}$ & $\mathrm{SI}$ & $\mathrm{NO}$ \\
\hline & $\mathrm{SI}$ & NO & NO & NO & $\mathrm{SI}$ & $\mathrm{SI}$ & $\mathrm{SI}$ & $\mathrm{SI}$ & $\mathrm{SI}$ & $\mathrm{SI}$ & NO & $\mathrm{SI}$ & $\mathrm{NO}$ & $\mathrm{SI}$ & $\mathrm{NO}$ & $\mathrm{SI}$ & $\mathrm{SI}$ & $\mathrm{SI}$ \\
\hline & NO & NO & NO & NO & NO & NO & $\mathrm{SI}$ & $\mathrm{SI}$ & $\mathrm{SI}$ & NO & NO & $\mathrm{SI}$ & NO & NO & NO & $\mathrm{SI}$ & $\mathrm{SI}$ & NO \\
\hline \multirow{16}{*}{$\begin{array}{l}\text { CREAR/ } \\
\text { DISEÑAR }\end{array}$} & $\mathrm{SI}$ & NO & NO & NO & NO & NO & $\mathrm{SI}$ & $\mathrm{SI}$ & $\mathrm{SI}$ & $\mathrm{SI}$ & NO & $\mathrm{SI}$ & NO & NO & NO & $\mathrm{SI}$ & NO & $\mathrm{SI}$ \\
\hline & $\mathrm{SI}$ & NO & NO & $\mathrm{SI}$ & $\mathrm{SI}$ & $\mathrm{SI}$ & $\mathrm{SI}$ & $\mathrm{SI}$ & $\mathrm{SI}$ & $\mathrm{SI}$ & $\mathrm{SI}$ & $\mathrm{SI}$ & NO & $\mathrm{SI}$ & $\mathrm{SI}$ & $\mathrm{SI}$ & $\mathrm{SI}$ & $\mathrm{SI}$ \\
\hline & $\mathrm{SI}$ & NO & NO & $\mathrm{SI}$ & NO & $\mathrm{SI}$ & $\mathrm{SI}$ & $\mathrm{SI}$ & $\mathrm{SI}$ & $\mathrm{SI}$ & $\mathrm{SI}$ & $\mathrm{SI}$ & NO & $\mathrm{SI}$ & $\mathrm{SI}$ & $\mathrm{SI}$ & $\mathrm{SI}$ & $\mathrm{SI}$ \\
\hline & NO & NO & NO & NO & $\mathrm{SI}$ & NO & NO & NO & NO & NO & NO & NO & NO & NO & NO & NO & NO & NO \\
\hline & $\mathrm{SI}$ & NO & NO & NO & NO & $\mathrm{SI}$ & $\mathrm{SI}$ & $\mathrm{SI}$ & $\mathrm{SI}$ & $\mathrm{SI}$ & $\mathrm{SI}$ & $\mathrm{SI}$ & NO & $\mathrm{SI}$ & NO & $\mathrm{SI}$ & NO & $\mathrm{SI}$ \\
\hline & $\mathrm{SI}$ & NO & NO & NO & NO & $\mathrm{SI}$ & NO & $\mathrm{SI}$ & $\mathrm{SI}$ & $\mathrm{SI}$ & $\mathrm{SI}$ & $\mathrm{SI}$ & NO & $\mathrm{SI}$ & $\mathrm{SI}$ & $\mathrm{SI}$ & $\mathrm{SI}$ & $\mathrm{SI}$ \\
\hline & NO & NO & NO & NO & NO & NO & NO & NO & $\mathrm{SI}$ & NO & NO & NO & NO & NO & NO & NO & NO & $\mathrm{SI}$ \\
\hline & NO & NO & NO & NO & NO & NO & NO & NO & NO & NO & NO & NO & $\mathrm{NO}$ & NO & NO & NO & NO & $\mathrm{SI}$ \\
\hline & $\mathrm{SI}$ & NO & NO & $\mathrm{SI}$ & NO & $\mathrm{SI}$ & $\mathrm{SI}$ & $\mathrm{SI}$ & $\mathrm{SI}$ & $\mathrm{SI}$ & $\mathrm{SI}$ & $\mathrm{SI}$ & NO & $\mathrm{SI}$ & $\mathrm{SI}$ & $\mathrm{SI}$ & $\mathrm{NO}$ & $\mathrm{NO}$ \\
\hline & $\mathrm{NO}$ & NO & NO & NO & NO & $\mathrm{NO}$ & NO & NO & $\mathrm{SI}$ & NO & $\mathrm{SI}$ & NO & NO & NO & NO & NO & NO & $\mathrm{NO}$ \\
\hline & NO & NO & NO & $\mathrm{SI}$ & NO & NO & NO & NO & $\mathrm{SI}$ & NO & $\mathrm{SI}$ & NO & NO & $\mathrm{SI}$ & NO & $\mathrm{SI}$ & NO & $\mathrm{SI}$ \\
\hline & NO & NO & NO & NO & NO & NO & NO & NO & NO & NO & NO & NO & NO & NO & NO & NO & NO & $\mathrm{NO}$ \\
\hline & NO & NO & NO & NO & NO & $\mathrm{SI}$ & $\mathrm{SI}$ & $\mathrm{SI}$ & NO & $\mathrm{SI}$ & NO & $\mathrm{SI}$ & NO & NO & NO & $\mathrm{SI}$ & NO & $\mathrm{SI}$ \\
\hline & NO & NO & NO & NO & $\mathrm{NO}$ & NO & NO & NO & $\mathrm{SI}$ & NO & NO & NO & $\mathrm{NO}$ & NO & NO & $\mathrm{SI}$ & $\mathrm{SI}$ & $\mathrm{SI}$ \\
\hline & NO & NO & NO & NO & $\mathrm{SI}$ & $\mathrm{SI}$ & NO & NO & $\mathrm{SI}$ & NO & NO & NO & NO & NO & NO & NO & NO & $\mathrm{SI}$ \\
\hline & $\mathrm{SI}$ & $\mathrm{SI}$ & NO & NO & NO & $\mathrm{SI}$ & $\mathrm{SI}$ & $\mathrm{SI}$ & $\mathrm{SI}$ & NO & NO & $\mathrm{SI}$ & NO & $\mathrm{SI}$ & $\mathrm{SI}$ & $\mathrm{SI}$ & NO & $\mathrm{SI}$ \\
\hline \multirow{8}{*}{ DESCRIBIR } & NO & NO & $\mathrm{NO}$ & $\mathrm{NO}$ & NO & NO & NO & NO & $\mathrm{SI}$ & NO & NO & NO & NO & NO & NO & NO & $\mathrm{SI}$ & $\mathrm{NO}$ \\
\hline & $\mathrm{SI}$ & NO & NO & $\mathrm{SI}$ & $\mathrm{SI}$ & $\mathrm{SI}$ & $\mathrm{SI}$ & $\mathrm{SI}$ & $\mathrm{SI}$ & $\mathrm{SI}$ & $\mathrm{SI}$ & $\mathrm{SI}$ & NO & NO & $\mathrm{SI}$ & $\mathrm{SI}$ & $\mathrm{SI}$ & $\mathrm{SI}$ \\
\hline & NO & NO & NO & NO & NO & NO & NO & NO & $\mathrm{SI}$ & $\mathrm{SI}$ & NO & NO & NO & NO & NO & NO & NO & $\mathrm{NO}$ \\
\hline & NO & NO & NO & NO & NO & NO & NO & NO & $\mathrm{SI}$ & $\mathrm{SI}$ & NO & NO & NO & & $\mathrm{NO}$ & $\mathrm{SI}$ & NO & $\mathrm{NO}$ \\
\hline & NO & NO & NO & NO & $\mathrm{NO}$ & NO & NO & $\mathrm{NO}$ & $\mathrm{SI}$ & NO & NO & NO & $\mathrm{NO}$ & $\mathrm{SI}$ & $\mathrm{SI}$ & $\mathrm{SI}$ & NO & $\mathrm{NO}$ \\
\hline & NO & NO & NO & NO & $\mathrm{NO}$ & $\mathrm{NO}$ & NO & NO & $\mathrm{SI}$ & NO & NO & NO & $\mathrm{NO}$ & NO & NO & NO & NO & $\mathrm{NO}$ \\
\hline & $\mathrm{SI}$ & NO & NO & $\mathrm{SI}$ & SI & NO & $\mathrm{SI}$ & $\mathrm{SI}$ & $\mathrm{SI}$ & $\mathrm{SI}$ & $\mathrm{SI}$ & $\mathrm{SI}$ & NO & NO & NO & $\mathrm{SI}$ & NO & $\mathrm{NO}$ \\
\hline & NO & NO & $\mathrm{NO}$ & $\mathrm{SI}$ & NO & $\mathrm{SI}$ & $\mathrm{SI}$ & $\mathrm{SI}$ & $\mathrm{SI}$ & $\mathrm{SI}$ & $\mathrm{SI}$ & $\mathrm{SI}$ & $\mathrm{NO}$ & NO & $\mathrm{NO}$ & $\mathrm{SI}$ & $\mathrm{SI}$ & $\mathrm{SI}$ \\
\hline \multirow{17}{*}{$\begin{array}{l}\text { ANALIZAR/ } \\
\text { INTERPRETAR }\end{array}$} & $\mathrm{SI}$ & NO & $\mathrm{SI}$ & NO & NO & $\mathrm{SI}$ & NO & NO & $\mathrm{SI}$ & NO & $\mathrm{SI}$ & $\mathrm{SI}$ & $\mathrm{SI}$ & NO & NO & $\mathrm{SI}$ & NO & NO \\
\hline & $\mathrm{SI}$ & NO & $\mathrm{SI}$ & NO & NO & $\mathrm{SI}$ & NO & $\mathrm{SI}$ & $\mathrm{SI}$ & NO & $\mathrm{SI}$ & $\mathrm{SI}$ & NO & NO & NO & $\mathrm{SI}$ & NO & NO \\
\hline & $\mathrm{SI}$ & NO & SI & NO & NO & NO & NO & $\mathrm{SI}$ & $\mathrm{SI}$ & NO & NO & NO & NO & NO & NO & $\mathrm{SI}$ & NO & NO \\
\hline & $\mathrm{SI}$ & NO & NO & NO & NO & NO & NO & NO & $\mathrm{SI}$ & $\mathrm{SI}$ & NO & $\mathrm{SI}$ & NO & NO & NO & $\mathrm{SI}$ & $\mathrm{SI}$ & NO \\
\hline & $\mathrm{SI}$ & NO & NO & $\mathrm{SI}$ & NO & NO & NO & NO & $\mathrm{SI}$ & $\mathrm{SI}$ & $\mathrm{SI}$ & $\mathrm{SI}$ & NO & NO & NO & $\mathrm{SI}$ & NO & $\mathrm{SI}$ \\
\hline & NO & NO & NO & NO & NO & NO & $\mathrm{SI}$ & NO & $\mathrm{SI}$ & NO & NO & & NO & NO & NO & $\mathrm{SI}$ & NO & NO \\
\hline & $\mathrm{SI}$ & NO & NO & NO & NO & $\mathrm{SI}$ & $\mathrm{SI}$ & NO & $\mathrm{SI}$ & NO & NO & $\mathrm{SI}$ & NO & NO & NO & $\mathrm{SI}$ & $\mathrm{SI}$ & NO \\
\hline & NO & NO & NO & NO & NO & $\mathrm{SI}$ & $\mathrm{SI}$ & NO & $\mathrm{SI}$ & $\mathrm{SI}$ & $\mathrm{SI}$ & $\mathrm{SI}$ & NO & NO & NO & $\mathrm{SI}$ & NO & $\mathrm{SI}$ \\
\hline & NO & NO & NO & NO & NO & NO & NO & NO & $\mathrm{SI}$ & $\mathrm{SI}$ & $\mathrm{SI}$ & $\mathrm{SI}$ & NO & NO & NO & $\mathrm{SI}$ & NO & $\mathrm{NO}$ \\
\hline & $\mathrm{NO}$ & NO & NO & NO & NO & NO & NO & NO & $\mathrm{SI}$ & NO & $\mathrm{SI}$ & NO & NO & $\mathrm{NO}$ & NO & NO & NO & $\mathrm{NO}$ \\
\hline & NO & NO & NO & NO & NO & NO & NO & NO & $\mathrm{SI}$ & NO & NO & $\mathrm{SI}$ & NO & NO & NO & $\mathrm{SI}$ & $\mathrm{SI}$ & $\mathrm{SI}$ \\
\hline & NO & NO & NO & NO & NO & $\mathrm{NO}$ & NO & NO & $\mathrm{SI}$ & $\mathrm{SI}$ & $\mathrm{SI}$ & $\mathrm{SI}$ & NO & NO & NO & $\mathrm{SI}$ & NO & $\mathrm{SI}$ \\
\hline & NO & NO & NO & NO & NO & $\mathrm{NO}$ & NO & NO & $\mathrm{SI}$ & NO & NO & NO & NO & NO & NO & NO & $\mathrm{SI}$ & NO \\
\hline & $\mathrm{SI}$ & NO & NO & NO & NO & $\mathrm{NO}$ & NO & $\mathrm{SI}$ & $\mathrm{SI}$ & NO & $\mathrm{SI}$ & $\mathrm{SI}$ & NO & NO & NO & $\mathrm{SI}$ & NO & NO \\
\hline & $\mathrm{SI}$ & $\mathrm{SI}$ & NO & NO & NO & $\mathrm{SI}$ & $\mathrm{SI}$ & $\mathrm{SI}$ & $\mathrm{SI}$ & $\mathrm{SI}$ & $\mathrm{SI}$ & $\mathrm{SI}$ & NO & $\mathrm{SI}$ & NO & $\mathrm{SI}$ & NO & $\mathrm{SI}$ \\
\hline & $\mathrm{SI}$ & NO & NO & NO & NO & $\mathrm{SI}$ & $\mathrm{SI}$ & $\mathrm{SI}$ & $\mathrm{SI}$ & $\mathrm{SI}$ & $\mathrm{SI}$ & $\mathrm{SI}$ & NO & NO & NO & $\mathrm{SI}$ & $\mathrm{SI}$ & $\mathrm{SI}$ \\
\hline & $\mathrm{SI}$ & NO & NO & NO & NO & $\mathrm{SI}$ & $\mathrm{SI}$ & $\mathrm{SI}$ & $\mathrm{SI}$ & $\mathrm{SI}$ & $\mathrm{SI}$ & $\mathrm{SI}$ & NO & NO & NO & $\mathrm{SI}$ & NO & NO \\
\hline \multirow{5}{*}{ EVALUAR } & $\mathrm{SI}$ & $\mathrm{SI}$ & $\mathrm{SI}$ & $\mathrm{NO}$ & NO & NO & $\mathrm{NO}$ & $\mathrm{SI}$ & $\mathrm{SI}$ & $\mathrm{SI}$ & NO & NO & $\mathrm{NO}$ & $\mathrm{NO}$ & NO & $\mathrm{SI}$ & NO & $\mathrm{SI}$ \\
\hline & $\mathrm{SI}$ & NO & $\mathrm{SI}$ & NO & $\mathrm{SI}$ & $\mathrm{SI}$ & $\mathrm{SI}$ & $\mathrm{SI}$ & $\mathrm{SI}$ & $\mathrm{SI}$ & $\mathrm{SI}$ & $\mathrm{SI}$ & NO & $\mathrm{SI}$ & NO & $\mathrm{SI}$ & NO & $\mathrm{NO}$ \\
\hline & NO & NO & NO & NO & NO & NO & NO & NO & $\mathrm{SI}$ & NO & NO & NO & NO & NO & NO & $\mathrm{SI}$ & NO & NO \\
\hline & NO & NO & NO & NO & NO & NO & NO & NO & $\mathrm{SI}$ & NO & $\mathrm{SI}$ & NO & NO & NO & NO & $\mathrm{SI}$ & NO & NO \\
\hline & $\mathrm{SI}$ & NO & NO & $\mathrm{SI}$ & NO & $\mathrm{SI}$ & $\mathrm{SI}$ & $\mathrm{SI}$ & $\mathrm{SI}$ & $\mathrm{SI}$ & $\mathrm{SI}$ & $\mathrm{SI}$ & NO & NO & NO & $\mathrm{SI}$ & NO & $\mathrm{SI}$ \\
\hline
\end{tabular}


Diseño de una herramienta de evaluación de apps... - C. Gómez, A. Rico y O. Fontal

permiten desarrollar o poner en práctica, destacando de manera positiva la asociación libre de ideas, la observación, comparación, clasificación, ordenación, visualización y el desarrollo de destrezas perceptuales.

La siguiente dimensión sobre la que se realiza la comparativa de Apps, quizás sea una de las más difíciles de interpretar por su condición más subjetiva. Su evaluación está realizada en base a una posible aplicación creativa en el aula, por lo que los datos arrojados en esta tabla no pueden ser tomados como definitorios, puesto que dependen de una experiencia en la práctica educativa de manera más empírica. De la visión de la evaluadora, sin embargo, se puede extraer el cumplimiento positivo de ciertos indicadores que sí mantienen estrecha relación con el proceso creativo que se intenta fomentar desde las Apps.

Respecto a construir conocimiento y contextualizar, la mayoría de Apps permiten el acceso a otros materiales estáticos, sobre todo la observación y la visualización. No permiten realizar tormentas de ideas, investigar e identificar desde las propias Apps. Claramente parece que no permiten realizar visitas virtuales a lugares de interés relacionados con arte. Respecto al criterio de aplicar, permiten en su mayoría las acciones de: seleccionar, practicar, experimentar, desarrollar, transformar, recombinar, todo ello con relación a la teoría y práctica artística.

Por otra parte, y, referidos al criterio crear y diseñar, se manifiesta posible desde las Apps elegidas diseñar/crear obras en dos dimensiones y crear muestras. Crear animaciones solamente se puede realizar desde una App de las seleccionadas, así como crear películas. El criterio describir se manifiesta en negativo o ausente desde las Apps, excepto en los indicadores referidos a demostrar y compartir y presentar. Llegados al criterio de analizar e interpretar, se observa que se manifiesta ausente o negativo, excepto en los indicadores de edición, revisión y comunicación que permiten las Apps analizadas. Por último, respecto al criterio evaluar, se concluye que las Apps elegidas permiten inventariar y juzgar.

Dos de las tres Apps con las que se trabajó en el aula cumplen el estándar de fomentar la creatividad, siendo la que mayor porcentaje alcanza (APA16)Picsart, seguido de (ASM18)Stop Motion. (AP17)Pixton se queda bastante por debajo del estándar en esta dimensión.

La última dimensión comparada es la "Satisfacción”. Esta dimensión es también subjetiva. Desde la visión de la evaluadora, en general, se observa un predominio de los aspectos positivos, que son claramente manifiestos en los criterios de placer, en cuanto al disfrute durante la utilización de las Apps, y satisfacción mientras se aprende. En cuanto al criterio de fomento de la creatividad, se pone de manifiesto que estimulan procesos creativos y divergentes, y que permiten realizar todas las fases del proceso creativo. El criterio referido a la promoción de la motivación resulta altamente cumplido en casi todas las Apps. 
Tabla 9. Comparativa de la dimensión Satisfacción. Fuente: Elaboración propia

\begin{tabular}{|c|c|c|c|c|c|c|c|c|c|c|c|c|c|c|c|c|c|c|}
\hline & $\overrightarrow{\frac{1}{4}}$ & $\frac{d}{2}$ & 罩 & 享 & 峉 & 过 & 产 & $\frac{\infty}{<}$ & 岁 & 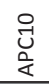 & $\overrightarrow{0}$ & ت̃ & $\underset{\vec{y}}{\overrightarrow{3}}$ & $\frac{\pi}{\tilde{Q}}$ & $\stackrel{\text { ñ }}{\frac{1}{4}}$ & 草 & $\hat{\vec{\alpha}}$ & $\sum_{<}^{\infty}$ \\
\hline PLACER & $\mathrm{SI}$ & $\mathrm{SI}$ & $\mathrm{SI}$ & $\mathrm{SI}$ & SI & SI & $\mathrm{SI}$ & $\mathrm{SI}$ & $\mathrm{SI}$ & SI & $\mathrm{SI}$ & $\mathrm{SI}$ & $\mathrm{SI}$ & NO & SI & $\mathrm{SI}$ & NO & $\mathrm{SI}$ \\
\hline FACILIDAD & $\mathrm{Sl}$ & $\mathrm{SI}$ & $\mathrm{SI}$ & NO & NO & NO & $\mathrm{SI}$ & $\mathrm{SI}$ & $\mathrm{SI}$ & NO & $\mathrm{SI}$ & NO & $\mathrm{SI}$ & NO & NO & $\mathrm{SI}$ & NO & $\mathrm{SI}$ \\
\hline \multirow{4}{*}{$\begin{array}{l}\text { SATISFACCIÓN } \\
\text { ASPECTOS }\end{array}$} & $\mathrm{SI}$ & $\mathrm{SI}$ & $\mathrm{SI}$ & $\mathrm{SI}$ & $\mathrm{SI}$ & $\mathrm{SI}$ & $\mathrm{SI}$ & $\mathrm{SI}$ & NO & $\mathrm{SI}$ & $\mathrm{SI}$ & NO & $\mathrm{SI}$ & $\mathrm{NO}$ & $\mathrm{SI}$ & $\mathrm{SI}$ & $\mathrm{NO}$ & $\mathrm{SI}$ \\
\hline & $\mathrm{SI}$ & $\mathrm{SI}$ & $\mathrm{SI}$ & $\mathrm{SI}$ & $\mathrm{SI}$ & $\mathrm{SI}$ & $\mathrm{SI}$ & $\mathrm{SI}$ & $\mathrm{SI}$ & $\mathrm{SI}$ & $\mathrm{SI}$ & $\mathrm{SI}$ & $\mathrm{SI}$ & NO & NO & $\mathrm{SI}$ & NO & $\mathrm{SI}$ \\
\hline & $\mathrm{SI}$ & $\mathrm{SI}$ & $\mathrm{SI}$ & $\mathrm{NO}$ & $\mathrm{NO}$ & $\mathrm{NO}$ & NO & $\mathrm{SI}$ & $\mathrm{SI}$ & $\mathrm{SI}$ & NO & NO & $\mathrm{SI}$ & NO & NO & $\mathrm{SI}$ & NO & NO \\
\hline & $\mathrm{SI}$ & $\mathrm{SI}$ & NO & NO & NO & $\mathrm{NO}$ & $\mathrm{SI}$ & $\mathrm{SI}$ & $\mathrm{SI}$ & NO & $\mathrm{SI}$ & NO & $\mathrm{SI}$ & $\mathrm{NO}$ & NO & $\mathrm{SI}$ & NO & $\mathrm{SI}$ \\
\hline \multirow{5}{*}{$\begin{array}{l}\text { FOMENTO } \\
\text { CREATIVIDAD }\end{array}$} & $\mathrm{SI}$ & $\mathrm{SI}$ & $\mathrm{SI}$ & $\mathrm{SI}$ & $\mathrm{NO}$ & NO & NO & $\mathrm{SI}$ & $\mathrm{SI}$ & NO & $\mathrm{SI}$ & $\mathrm{SI}$ & $\mathrm{SI}$ & NO & NO & $\mathrm{SI}$ & $\mathrm{SI}$ & $\mathrm{SI}$ \\
\hline & $\mathrm{SI}$ & NO & NO & $\mathrm{SI}$ & $\mathrm{SI}$ & $\mathrm{SI}$ & $\mathrm{SI}$ & $\mathrm{SI}$ & $\mathrm{SI}$ & $\mathrm{SI}$ & $\mathrm{SI}$ & $\mathrm{SI}$ & NO & $\mathrm{SI}$ & $\mathrm{SI}$ & $\mathrm{SI}$ & $\mathrm{SI}$ & $\mathrm{SI}$ \\
\hline & $\mathrm{SI}$ & $\mathrm{SI}$ & $\mathrm{SI}$ & NO & $\mathrm{NO}$ & NO & NO & $\mathrm{SI}$ & $\mathrm{SI}$ & $\mathrm{SI}$ & NO & $\mathrm{SI}$ & $\mathrm{SI}$ & NO & NO & $\mathrm{SI}$ & NO & NO \\
\hline & $\mathrm{SI}$ & $\mathrm{SI}$ & $\mathrm{NO}$ & $\mathrm{SI}$ & $\mathrm{NO}$ & $\mathrm{NO}$ & NO & $\mathrm{SI}$ & $\mathrm{SI}$ & NO & NO & $\mathrm{SI}$ & NO & $\mathrm{NO}$ & NO & 8 & NO & $\mathrm{SI}$ \\
\hline & $\mathrm{SI}$ & NO & NO & NO & NO & $\mathrm{SI}$ & $\mathrm{SI}$ & $\mathrm{SI}$ & $\mathrm{SI}$ & $\mathrm{SI}$ & $\mathrm{SI}$ & $\mathrm{SI}$ & NO & NO & $\mathrm{SI}$ & SI & NO & $\mathrm{SI}$ \\
\hline \multirow{5}{*}{ MOTIVACIÓN } & $\mathrm{SI}$ & $\mathrm{SI}$ & NO & $\mathrm{SI}$ & $\mathrm{SI}$ & $\mathrm{SI}$ & $\mathrm{SI}$ & $\mathrm{SI}$ & $\mathrm{SI}$ & $\mathrm{SI}$ & $\mathrm{SI}$ & $\mathrm{SI}$ & $\mathrm{SI}$ & $\mathrm{SI}$ & $\mathrm{SI}$ & $\mathrm{SI}$ & NO & $\mathrm{SI}$ \\
\hline & $\mathrm{SI}$ & $\mathrm{SI}$ & NO & NO & NO & NO & $\mathrm{SI}$ & $\mathrm{SI}$ & $\mathrm{SI}$ & $\mathrm{SI}$ & $\mathrm{SI}$ & $\mathrm{SI}$ & $\mathrm{SI}$ & NO & SI & & $\mathrm{SI}$ & NO \\
\hline & $\mathrm{SI}$ & $\mathrm{SI}$ & $\mathrm{SI}$ & $\mathrm{SI}$ & $\mathrm{SI}$ & NO & $\mathrm{SI}$ & $\mathrm{SI}$ & $\mathrm{SI}$ & $\mathrm{SI}$ & $\mathrm{SI}$ & NO & $\mathrm{SI}$ & NO & $\mathrm{SI}$ & $\mathrm{SI}$ & NO & $\mathrm{SI}$ \\
\hline & $\mathrm{SI}$ & $\mathrm{SI}$ & $\mathrm{SI}$ & $\mathrm{SI}$ & SI & $\mathrm{SI}$ & $\mathrm{SI}$ & $\mathrm{SI}$ & $\mathrm{SI}$ & $\mathrm{SI}$ & $\mathrm{SI}$ & $\mathrm{SI}$ & $\mathrm{SI}$ & NO & $\mathrm{SI}$ & $\mathrm{SI}$ & NO & $\mathrm{SI}$ \\
\hline & $\mathrm{SI}$ & $\mathrm{SI}$ & $\mathrm{SI}$ & $\mathrm{SI}$ & NO & NO & $\mathrm{sl}$ & $\mathrm{SI}$ & $\mathrm{SI}$ & NO & $\mathrm{SI}$ & $\mathrm{SI}$ & $\mathrm{SI}$ & NO & $\mathrm{SI}$ & $\mathrm{SI}$ & NO & $\mathrm{SI}$ \\
\hline \multirow{3}{*}{ EFECTIVIDAD } & $\mathrm{SI}$ & $\mathrm{SI}$ & $\mathrm{SI}$ & $\mathrm{SI}$ & $\mathrm{SI}$ & NO & $\mathrm{SI}$ & $\mathrm{SI}$ & $\mathrm{SI}$ & $\mathrm{SI}$ & $\mathrm{SI}$ & $\mathrm{SI}$ & $\mathrm{ST}$ & NO & NO & $\mathrm{SI}$ & $\mathrm{SI}$ & $\mathrm{SI}$ \\
\hline & $\frac{\mathrm{SI}}{\mathrm{SI}}$ & $\frac{\mathrm{SI}}{\mathrm{SI}}$ & NO & $\frac{\mathrm{SI}}{\mathrm{SI}}$ & $\mathrm{SI}$ & $\mathrm{SI}$ & $\mathrm{SI}$ & $\frac{\mathrm{SI}}{\mathrm{SI}}$ & $\mathrm{SI}$ & $\mathrm{SI}$ & $\mathrm{SI}$ & NO & $\mathrm{SI}$ & NO & $\mathrm{SI}$ & $\mathrm{SI}$ & $\mathrm{SI}$ & $\mathrm{SI}$ \\
\hline & $\mathrm{SI}$ & NO & NO & NO & $\mathrm{SI}$ & $\mathrm{SI}$ & $\mathrm{SI}$ & $\mathrm{SI}$ & $\mathrm{SI}$ & $\mathrm{SI}$ & $\mathrm{SI}$ & $\mathrm{SI}$ & NO & $\mathrm{SI}$ & NO & $\mathrm{SI}$ & $\mathrm{SI}$ & $\mathrm{SI}$ \\
\hline \multirow{2}{*}{ EFICIENCIA } & $\mathrm{SI}$ & $\mathrm{SI}$ & $\mathrm{SI}$ & $\mathrm{SI}$ & $\mathrm{SI}$ & $\mathrm{NO}$ & $\mathrm{SI}$ & $\mathrm{SI}$ & $\mathrm{SI}$ & $\mathrm{SI}$ & $\mathrm{SI}$ & NO & $\mathrm{SI}$ & NO & $\mathrm{SI}$ & $\mathrm{SI}$ & $\mathrm{SI}$ & $\mathrm{SI}$ \\
\hline & $\mathrm{SI}$ & $\mathrm{SI}$ & $\mathrm{SI}$ & $\mathrm{SI}$ & $\mathrm{SI}$ & NO & $\mathrm{SI}$ & $\mathrm{SI}$ & $\mathrm{SI}$ & $\mathrm{s}$ & $\mathrm{s}$ & NO & $\mathrm{SI}$ & NO & SI & & $\mathrm{SI}$ & $\mathrm{SI}$ \\
\hline \multirow{2}{*}{$\begin{array}{l}\text { SATISFACCIÓN } \\
\text { GENERAL }\end{array}$} & $\mathrm{SI}$ & NO & $\mathrm{SI}$ & $\mathrm{SI}$ & $\mathrm{SI}$ & $\mathrm{SI}$ & $\mathrm{SI}$ & $\mathrm{SI}$ & $\mathrm{SI}$ & $\mathrm{SI}$ & $\mathrm{SI}$ & NO & $\mathrm{SI}$ & NO & $\mathrm{SI}$ & $\mathrm{SI}$ & $\mathrm{SI}$ & $\mathrm{SI}$ \\
\hline & $\mathrm{SI}$ & SI & $\mathrm{SI}$ & $\mathrm{SI}$ & $\mathrm{SI}$ & $\mathrm{SI}$ & $\mathrm{SI}$ & $\mathrm{SI}$ & $\mathrm{SI}$ & $\mathrm{SI}$ & $\mathrm{SI}$ & $\mathrm{SI}$ & $\mathrm{SI}$ & NO & $\mathrm{SI}$ & $\mathrm{SI}$ & NO & $\mathrm{SI}$ \\
\hline
\end{tabular}

Respecto a los criterios de efectividad, también se puede señalar que se manifiestan positivos, sobre todo el hecho de que permiten resolver tareas en un tiempo limitado y con éxito al primer intento, además de permitir aprender varias tareas en cada exploración. Destaca positivamente la eficiencia de las Apps, y la satisfacción en sus indicadores de facilidad para utilizar las Apps y lo que agrada su utilización.

\section{CONGLUSIONES}

Las conclusiones a este artículo las definiremos en base a las mejoras que deben presentar las Apps educativas en base a los puntos fuertes y carencias encontrados en las Apps evaluadas.

Respecto a esto, observamos que las Apps tendrían que incluir una descripción más completa de lo que ofrecen, así como los objetivos que permiten y la edad a la que están destinadas. Eso evitaría como docentes el rastreo y exploración durante bastante tiempo. Para que puedan ser realmente utilizadas por los alumnos es necesario que sean agradables, fáciles de usar y autoexplicativas, de manera que ellos puedan utilizarlas inmediatamente sin tener que realizar una exhaustiva lectura de instrucciones ni largas tareas previas de descarga.

La inclusión de índices, sumarios o los mapas conceptuales para ayudar a situarse respecto al contenido que se plantea y los objetivos que se proponen son unos 
Diseño de una herramienta de evaluación de apps... - C. Gómez, A. Rico y O. Fontal

elementos que añaden calidad a la App. El índice no debe ser demasiado genérico, debiéndose hacer una idea clara de lo que encontrará en cada uno de los apartados. En cada momento los estudiantes deberían conocer el lugar de la App donde se encuentra y tener la posibilidad de moverse según sus preferencias: retroceder, avanzar, etc.

La instalación de la App debe ser sencilla y rápida y deben ser fácilmente integrables con otros medios didácticos en los diferentes contextos formativos, para que se puedan adaptar a diversos entornos, estrategias didácticas (trabajo individual, grupo cooperativo o competitivo,) y usuarios (circunstancias culturales y necesidades formativas). La velocidad entre el usuario y la App (animaciones, lectura de datos) debe ser adecuada. La ejecución de la App debería ser fiable, sin contener errores de funcionamiento. Se debería ofrecer la posibilidad de diseñar el propio itinerario según los objetivos y los contenidos que se trabajen en cada apartado. Deberían ofrecer ayuda en la selección de itinerarios o una ayuda o guía para seleccionar el más adecuado.

Además, tendrían que incluir un sistema de evaluación y seguimiento (control) con informes de las actividades realizadas: temas, nivel de dificultad, tiempo invertido, errores, itinerarios seguidos para resolver los problemas, etc.). Por este motivo es importante que los alumnos puedan ir comprobando y autoevaluando el propio proceso de aprendizaje. Algunas actividades de evaluación debieran permitir comprobar la adquisición de los aprendizajes de cada fase o bloque, de manera que se pudiese decidir continuar adelante o bien repasar aquello que no se ha acabado de asimilar. Cabe remarcar que en este punto se hace referencia a una evaluación durante el proceso de aprendizaje que ayude a mejorarlo. Las actividades de evaluación sobre el proceso de aprendizaje permiten que los alumnos valoren las propias dificultades y carencias respecto a los aprendizajes propuestos y que haga un nuevo esfuerzo para superarlas.

Cuando los alumnos detectan que el grado de adquisición de los aprendizajes es suficiente, tienen que tener la posibilidad de aumentar el grado de dificultad de los siguientes, de manera que éstos continúen siendo un objetivo de aprendizaje suficientemente interesante. Además de la evaluación del proceso, sería interesante hacer una evaluación final, para que los alumnos tengan una idea de la situación en que está respecto a los aprendizajes propuestos. Esta evaluación permitiría ser consciente del propio progreso y estimularía de cara a nuevos aprendizajes, de la misma manera que le avisaría si necesita reforzar el trabajo cuando los resultados no son adecuados.

Los mejores aprendizajes siempre dejan al estudiante con el deseo de aprender más. Por esta razón, a un alumno que ha aprendido y ha alcanzado un buen nivel respecto al tema trabajado le interesaría recibir información o propuestas de cómo puede continuar aprendiendo sobre el tema tratado. Cuando el resultado de la evaluación final no es suficientemente satisfactorio, también es interesante hacerlo 
saber a los alumnos y estimularlos para que continúen trabajando sobre el tema, a partir de las propuestas de la propia App. También deberían permitir continuar los trabajos empezados con anterioridad.

La información que se presenta debería ser correcta y actual, y estar bien estructurada. Los textos no deberían tener faltas de ortografía y la construcción de las frases debe ser correcta. Una buena estructuración de la App permitiría acceder bien a los contenidos, actividades, niveles y prestaciones en general. (El sistema de navegación debe permitir que el usuario tenga el control. Puede ser: lineal, paralelo, ramificado, etc.)

Para que el aprendizaje sea significativo es necesario que el contenido sea potencialmente significativo para el estudiante y que éste tenga la voluntad de aprender significativamente, relacionando los nuevos contenidos con el conocimiento almacenado en sus esquemas mentales. Por ello se hace necesario incluir preguntas para orientar la relación de los nuevos conocimientos con los conocimientos anteriores de los estudiantes. Además, deberían facilitar aprendizajes transferibles a otras situaciones mediante una continua actividad mental en consonancia con la naturaleza de los aprendizajes que se pretenden.

Para posibilitar el grado de concentración, se recomienda evitar la publicidad, o por lo menos que ésta apareciese diferenciada del resto de la interfaz, no interrumpiendo la secuencia de aprendizaje. Además, no debería tener acceso a enlaces para pagar otros atributos de la App, y si los tiene debería contener una advertencia antes de su descarga. Con el fin de centrar la atención es deseable que utilicen organizadores previos al introducir los temas, síntesis, resúmenes y esquemas. También es de esperar que empleen diversos códigos comunicativos: usar códigos verbales (su construcción es convencional y requieren un gran esfuerzo de abstracción) y códigos icónicos (que muestran representaciones más intuitivas y cercanas a la realidad).

Lo ideal es que se propongan diversos tipos de actividades permitiendo diversas formas de utilización y de acercamiento al conocimiento. Se recomienda la posibilidad de escoger la presentación de una misma información con sonido o visualmente para facilitar el uso de la App a personas con deficiencias visuales o auditivas. Respecto a la relación entre la información y los objetivos de aprendizaje, es recomendable que los objetivos estén presentes a lo largo de toda la App para que los alumnos sean conscientes de que la información contribuye a alcanzar los objetivos.

No se puede finalizar este epígrafe sin hacer mención a la necesidad de diversidad de los trabajos propuestos en el aula. En este sentido, se afirma que la variedad de éstos estimula el aprendizaje, ya que invita a los estudiantes a prestar más atención a lo que le ofrece el material. Respecto a este punto, se trata de encontrar la estabilidad entre la claridad de la información y la variedad de las actividades. La variedad de 
Diseño de una herramienta de evaluación de apps... - C. Gómez, A. Rico y O. Fontal

los trabajos y las presentaciones ayuda a los alumnos a prestar más atención, es por ello por lo que entendemos que el uso del m-learning en el aula aporta diversidad de actividades y entornos que potencian el aprendizaje, que, además, puede ser ampliado más allá del espacio escolar.

\section{BIBLIOGRAFÍA}

Area, Manuel (2005). La educación en el laberinto tecnológico. Barcelona: Octaedro.

Asensio, Mikel, Santacana, Joan y Asenjo, Elena (2018). Evaluación de aplicación desde la usabilidad. Estudios empíricos y racionales. En Joan Santacana, Mikel Asensio, Victoria López y Tania Martínez (coords.) (2018). La evaluación de las “apps” en el patrimonio cultural. Gijón: Trea, pp. 107-147.

Baumgartner, Peter y Payr, Sabine (1996). Learning as action: A social science approach to the evaluation of interactive media. En actas de Proceedings of ED-MEDIA 96-World Conference on Educational Multimedia and Hypermedia, pp. 31-37. Disponible en: https://pdfs.semanticscholar.org/3ddb/6881a1d6f3638fbfa1a0e908ed2ea37da4de. pdf

Brazuelo, Francisco y Gaello, Domingo, J. (2011). Mobile learning: los dispositivos móviles como recurso educativo. Sevilla: MAD. Cabero, Julio Y Llorente, Carmen (2013). La aplicación del juicio de experto como técnica de evaluación de las tecnologías de la información (TIC). Eduweb: Revista de Tecnología de Información y Comunicación en Educación, 7 (2), pp. 11-22. Disponible en: https://recyt.fecyt. es/index.php/BORDON/article/view/brp.2013.65202

Cacheiro, Maria Luz (2010). Diseño de medios didácticos y TIC aplicadas a la enseñanza. En Mario Alberto Secchi y Antonio Medina (coords.). Didáctica aplicada a la medicina y ciencias de la salud. Rosario (Argentina): Instituto Universitario Italiano de Rosario, pp. 61-90.

Cuello, Javier y Vittone, José (2013). Diseñando Apps para móviles. [S.1.]: Catalina Duque Giraldo.Disponible en: https://books.google.es/books? id=ATiqsjH1rvwC\&printsec $=$ frontcover\&hl=es\&source $=$ gbs_ge_summa $\mathrm{ry} \_\mathrm{r} \& \mathrm{cad}=0 \# \mathrm{v}=$ onepage $\& \mathrm{q} \& \mathrm{f}=$ false

Deterline, Willam (1965). Introducción a la enseñanza programada. Buenos Aires: Troquel.

Enríquez, Gabriel y Casas, Isabel (2013). Usabilidad en aplicaciones móviles. Informes Cientificos-Técnicos UNPA, 5 (2), pp. 25-47.

Fontal, Olaia (2016). El Observatorio de Educación Patrimonial en España. Cultura y Educación, 28, (1), pp. 261-266. DOI: 10.1080/11356405.2015.1110374

González-Suárez, Saray (2011). Identificación y evaluación de las herramientas de valoración de ideas. (Trabajo fin de Máster). Logroño: Universidad de la Rioja. Disponible en: biblioteca.unirioja.es/tfe_e/TFE000113.pdf 
Ibáñez-Etxeberria, Alex, Asensio, Mikel, Vicent, Naiara Y Cuenca, José María (2012). Mobile devices: a tool for tourism and learning at archaeological sites. International Journal of Web Based Communities, 8 (1), pp. 57-72. DOI: 10.1504/ IJWBC.2012.044682

Kortabitarte, Aroia, Ibáñez-Etxeberria, Alex, Luna, Ursula, Vicent, Naiara, Gillate, Iratxe, Molero, Bergona y Kintana, Jurji (2017) Dimensiones para la evaluación de aprendizajes en APPs sobre patrimonio. Pulso: revista de educación, 40, pp. 17-33.

Lowenfeld, Victor Y Brittain, W. Lambert (1984). Desarrollo de la capacidad creadora. Madrid: Kapelusz.

Marín, Sofía, García-Ceballos, Silvia, Vicent, Naiara, Guillate, Iratxe y Gómez-Redondo, Carmen (2017). Educación patrimonial inclusiva en OEPE: un estudio prospectivo Revista de Educación, 375, 110-135. DOI: 10.4438/1988-592X-RE-2016-375-337

Martínez, Tania (2014). Actividades de mobile learning para el patrimonio históricoartístico y monumental: ejemplos de aplicación. En Joan Santacana y Laia Coma (coords.). El m_learning y la educación patrimonial. Gijón: Trea, pp. 139-154.

Nielsen, Jakob (1995). Multimedia and hypertext: The Internet and beyond. San Francisco: Morgan Kaufmann

Peña, Francisco David; Hidalgo, Carmen y Palacios, Antonio J. (2015). Las nuevas tecnologías y la educación en el ámbito del patrimonio cultural. «Madrid Industrial, Itinerarios». Un ejemplo de m-learning aplicado al patrimonio industrial. Revista Tecnología, Ciencia y Educación, 2, pp. 51-82.https://tecnologia-ciencia-educacion. com/index.php/TCE/article/view/52

Prieto, Silvia (2015). Criterios para la utilización y diseño de aplicaciones móviles educativas. Consultado en: http://www.educaweb.com/noticia/2015/04/29/ criterios-utilizacion-diseno-aplicaciones-moviles-educativas-8814/

Santacana, Joan y Coma, Laia. (Coords.) (2014). El m_learning y la educación patrimonial. Gijón: Trea.

Santacana, Joan, Asensio, Mikel, López, Victoria y Martínez, Tania (coords.) (2018). La evaluación de las "apps" en el patrimonio cultural. Gijón: Trea.

Santiago, Raúl (2013). Tecnología móvil e innovación en el aula: Nuevos retos y realidades educativas. En Rosa María Goig (dir.). Formación del profesorado en la sociedad digital: investigación e innovación y recursos didácticos. Madrid: UNED, pp. 219-239.

Soriano, Ana María (2014). Diseño y validación de instrumentos de medición. San Salvador: Universidad Don Bosco.

Stake, Robert (2006). Evaluación comprensiva y evaluación basada en estándares. Barcelona: Ariel.

Vicent, Naiara (2013). Evaluación de un programa de educación patrimonial basado en tecnología móvil. (Tesis doctoral). Universidad Autónoma de Madrid. Disponible en: https://repositorio.uam.es/bitstream/handle/10486/14321/66930_tesis_Vicent_ Naiara.pdf? sequence $=7$ 

PARTE DEL ALUMNADO.

\begin{tabular}{|c|c|}
\hline \multicolumn{2}{|c|}{ HERRAMIENTA DE ANÁLISIS DE APPS } \\
\hline \multicolumn{2}{|c|}{$\begin{array}{l}\text { De todas estas acciones, debes señalar aquellas que has llevado a la práctica durante la experiencia } \\
\text { realizada. Debes tener en cuenta, por un lado, lo que te ha permitido poner en práctica la propia App, } \\
\text { así como el contexto, la metodología y el proceso de enseñanza _aprendizaje llevados a cabo. } \\
\text { Selecciona todos los que correspondan. }\end{array}$} \\
\hline $\begin{array}{l}\text { Construir } \\
\text { conocimiento/ } \\
\text { Conceptualizar }\end{array}$ & $\begin{array}{l}\text { - Observar (larga y fijamente): discutir temas que se relacionan con la observación } \\
\text { - como las concepciones de poder, realidad, representación natural y estereotipada } \\
\text { en las artes visuales. Intercambiar ideas sobre la creación del arte y objetos } \\
\text { culturales con pares y otras audiencias. } \\
\text { - Jugar (explorar diferentes dimensiones del juego: solitario, paralelo, asociativo, } \\
\text { cooperativo, de simulación, de observación, con el entorno, fantasioso/imaginativo, } \\
\text { juego de roles histórico, etc). }\end{array}$ \\
\hline Aplicar & $\begin{array}{l}\text { - Seleccionar (elegir objetos, materiales, procesos, técnicas y métodos apropiados } \\
\text { en arte). } \\
\text { - Practicar (técnicas, métodos y procesos en artes visuales en forma individual o } \\
\text { colaborativa). } \\
\text { - Experimentar (manipular y experimentar con disciplinas, materiales, formas y } \\
\text { conceptos). Transformar (objetos y espacios cotidianos en obras de arte). } \\
\text { - Recombinar (crear mezclas que recombinan diferentes materiales y conceptos } \\
\text { artísticos) Seleccionar varias obras y las organizarlas en una muestra de arte o en } \\
\text { una recopilación de obras. }\end{array}$ \\
\hline Crear/Diseñar & $\begin{array}{l}\text { - Crear una obra 2D (pinturas, historietas, caricaturas, técnicas mixtas, impresiones, } \\
\text { bocetos, fotografías, montajes fotográficos, tarjetas, ilustraciones, obras de arte } \\
\text { secuenciales). } \\
\text { - Crear un objeto cultural virtual (aplicaciones, narraciones digitales, podcasts, } \\
\text { arte digital, imágenes digitales, imágenes, animación, robótica, juegos, diseños } \\
\text { interactivos, simulación...). } \\
\text { - Grabar (crear grabaciones basadas en guiones alrededor de conceptos artísticos). }\end{array}$ \\
\hline Describir & - Presentar (compartir ideas, procesos y/o trabajo artístico). \\
\hline $\begin{array}{l}\text { Analizar / } \\
\text { Interpretar }\end{array}$ & $\begin{array}{l}\text { - Indagar/Investigar (cuestiones estéticas, indagaciones sobre experiencias, } \\
\text { recuerdos, técnicas e ideas en artes visuales). } \\
\text { - Caracterizar (captar y expresar características distintivas de los procesos y obras de } \\
\text { arte visual). } \\
\text { - Editar (sus obras usando distintas herramientas). } \\
\text { - Revisar (revisar, reelaborar y reorganizan elementos, eliminando y/o remplazando) }\end{array}$ \\
\hline Evaluar & $\begin{array}{l}\text { - Juzgar (formar opiniones y emiten juicios sobre el trabajo, evaluaciones entre } \\
\text { pares y críticas grupales). }\end{array}$ \\
\hline
\end{tabular}


Tabla 1. Criterios y estándares de la dimensión de Usabilidad. Fuente: Elaboración propia

DIMESIÓN: USABILIDAD

CRITERIOS ESTÁDNARES

La App es gratuita

La descarga de la App es rápida

ACCESO El formato de la App es estándar y puede ser leído por su navegador

La ejecución de la App es fiable

La velocidad de acceso es adecuada

La App no contiene enlaces rotos

En la App se indica el modo de contactar con el autor

Existe en la App un enlace a las fuentes externas que pueda utilizarse para realizar reclamaciones $\mathrm{y} / \mathrm{o}$ sugerencias

En la App se incluyen enlacen a los datos originales

Incluye la App un enlace a la pantalla principal

ENLACES En el caso de enlaces que remitan a documentos en servidores externos, se indica al usuario que está abandonando la App

La App incluye un motor de búsqueda interno para facilitar a los usuarios la

localización fácil y rápida de la información

La App le conduce a otros enlaces de interés

La App incluye un enlace al mapa del sitio, índice o tabla de contenidos

Para sitios organizados en jerarquías, se incluye enlace a la página de nivel superior

\begin{tabular}{|c|c|}
\hline \multirow{2}{*}{ LENGUAJE } & El lenguaje de la App es adecuado \\
\hline & La App posee carácter multilingüe \\
\hline MEMORABILIDAD & $\begin{array}{l}\text { Resulta suficiente en número de pasos, clics o pantallas usadas para terminar una } \\
\text { tarea después de no usar la aplicación por in periodo de tiempo }\end{array}$ \\
\hline ERRORES & La App no contiene errores \\
\hline \multirow{2}{*}{ CONTENIDO } & $\underline{\text { La cantidad de palabras por pantalla es adecuada }}$ \\
\hline & La cantidad total de imágenes es adecuada \\
\hline \multirow{2}{*}{ ACCESIBILIDAD } & El tamaño de la letra es ajustable \\
\hline & Las imágenes tienen texto alternativo \\
\hline \multirow{2}{*}{ SEGURIDAD } & El número de incidentes detectados permite realizar las tareas con normalidad \\
\hline & La cantidad de reglas de seguridad resulta positiva \\
\hline PORTABILIDAD & La App se acopla sin dificultad a diferentes dispositivos móviles \\
\hline \multirow{2}{*}{ CONTEXTO } & $\begin{array}{l}\text { La App, una vez descargada no necesita conexión a internet para poder trabajar con } \\
\text { ella }\end{array}$ \\
\hline & $\begin{array}{l}\text { Las características del dispositivo permiten la utilización de la App en diferentes } \\
\text { contextos }\end{array}$ \\
\hline \multirow{3}{*}{ IMÁGENES } & Existe un equilibrio entre imágenes y texto \\
\hline & El uso de color es adecuado \\
\hline & El movimiento de los elementos que aparecen en la App es adecuado \\
\hline \multirow{3}{*}{ INTERFAZ } & La App incluye esquemas o cuadros sinópticos \\
\hline & El diseño de iconos es claro e identificador \\
\hline & Las barras de herramier \\
\hline
\end{tabular}


Diseño de una herramienta de evaluación de apps... - C. Gómez, A. Rico y O. Fontal

Tabla 2. Criterios y estándares de la dimensión de Adecuación al Contenido.

Fuente: Elaboración propia

\begin{tabular}{|c|c|}
\hline \multicolumn{2}{|c|}{ DIMENSIÓN: ADECUACIÓN AL CONTENIDO } \\
\hline \multirow[t]{2}{*}{ ACTUALIZACIÓN } & La información en la App está actualizada \\
\hline & Se incluye la fecha de la ultima versión \\
\hline \multirow[t]{2}{*}{ ADECUACIÓN } & La App indica el rango de edad a la que va dirigida \\
\hline & La App permite buscar y editar datos \\
\hline \multirow[t]{3}{*}{ DOCUMENTACIÓN } & Se incluye una guía del profesor, del alumno u otro tipo de guía \\
\hline & Permite ampliar los contenidos con referencias bibliográficas u otros enlaces \\
\hline & Existe una hoja de trabajo con actividades complementarias \\
\hline \multirow[t]{7}{*}{ ESTRUCTURA } & La App incluye índice \\
\hline & La App contiene cuadro sinópticos o mapas conceptuales \\
\hline & Los cuadros sinópticos que contiene la App son fáciles de leer \\
\hline & Los contenidos de la App tienen una secuencia lógica \\
\hline & La organización de los contenidos favorece la transferencia \\
\hline & Si usted va a otro enlace existe una forma de regresar al inicio \\
\hline & La App contiene organizadores previos \\
\hline \multirow[t]{6}{*}{ CRÉDITOS } & Aparece el autor de la App \\
\hline & Es posible establecer contacto con el autor de la App \\
\hline & Aparece quién publicó el documento \\
\hline & En la App se indica la fecha de producción \\
\hline & $\begin{array}{l}\text { La App indica con claridad qué organización, persona o empresa es responsable de } \\
\text { los contenidos }\end{array}$ \\
\hline & La App indica el Copyright de la misma \\
\hline \multirow{6}{*}{$\begin{array}{l}\text { OTROS ELEMENTOS } \\
\text { TÉCNICOS }\end{array}$} & La App tiene sonidos \\
\hline & Se adecúa la banda al ritmo de las imágenes \\
\hline & La calidad del sonido es buena \\
\hline & El sonido aporta concentración o estados positivos para el desarrollo de las tareas \\
\hline & El sonido es original (creado específicamente para la App) \\
\hline & La App dispone de voz en off \\
\hline \multirow[t]{2}{*}{ FIABILIDAD } & La App suministra información sobre la garantía de los servicios ofrecidos \\
\hline & $\begin{array}{l}\text { La organización requiere información de los usuarios, indicando claramente de qué } \\
\text { modo será utilizada la información }\end{array}$ \\
\hline \multirow[t]{2}{*}{ PUBLICIDAD } & La App no contiene publicidad \\
\hline & $\begin{array}{l}\text { Si la App contiene publicidad, ésta permite el manejo de la App sin interferir de } \\
\text { forma negativa durante la actividad }\end{array}$ \\
\hline RELEVANCIA & La App es relevante dentro de su categoría de contenidos \\
\hline
\end{tabular}


Tabla 3. Criterios y estándares de la dimensión de Metodologías activas. Fuente: Elaboración propia

\begin{tabular}{|c|c|}
\hline \multirow{2}{*}{\multicolumn{2}{|c|}{$\begin{array}{lc}\text { DIMENSIÓN: } & \text { METODOLOGÍAS ACTIVAS } \\
\text { CRITERIOS } & \text { ESTÁNDARES }\end{array}$}} \\
\hline & \\
\hline \multirow{14}{*}{ ACTIVIDADES } & Las actividades tienen relación directa con los objetivos y contenidos \\
\hline & Las actividades son motivadoras \\
\hline & Las actividades fomentan la creatividad y la exploración \\
\hline & Las actividades favorecen la transferencia \\
\hline & La App contiene un mapa de navegación y breve descripción de las actividades \\
\hline & Tienen un enfoque aplicativo / creativo \\
\hline & La App contiene ejercicios de aplicación \\
\hline & La App recoge y muestra al alumno los resultados \\
\hline & La App informa sobre los errores cometidos \\
\hline & La App orienta al alumno en la secuencia de aprendizaje \\
\hline & La App permite comparar los resultados de todos los alumnos y los globales \\
\hline & La App propone ejercicios con varias soluciones válidas \\
\hline & La App permite corrección de errores \\
\hline & La App ayuda a aprender de los errores \\
\hline \multirow[b]{2}{*}{$\begin{array}{l}\text { CONOCIMIENTOS } \\
\text { PREVIOS }\end{array}$} & No requiere conocimientos previos sobre la materia que contiene la App \\
\hline & $\begin{array}{l}\text { No requiere otros conocimientos previos requeridos en el manejo de dispositivos } \\
\text { móviles }\end{array}$ \\
\hline \multirow{16}{*}{ CLARIDAD } & Se puede asegurar que la información es verídica \\
\hline & $\begin{array}{l}\text { Se indica con claridad si el material de la App ha sido tomado de una fuente de } \\
\text { información externa }\end{array}$ \\
\hline & $\begin{array}{l}\text { Están claramente establecidos los puntos de vista de la organización sobre aquello } \\
\text { que promociona }\end{array}$ \\
\hline & Claridad en la fecha de recogida de datos \\
\hline & Si la misma información también ha sido impresa, se indica \\
\hline & $\begin{array}{l}\text { Si la App incluye material de varias fuentes, se indica claramente de qué fuente } \\
\text { proviene cada fragmento }\end{array}$ \\
\hline & Está claro qué materiales se incluyen en la App \\
\hline & $\begin{array}{l}\text { Se indica claramente si se trata de una versión completa o qué partes del documento } \\
\text { original se han omitido }\end{array}$ \\
\hline & $\begin{array}{l}\text { La App informa claramente de las restricciones que afecten al uso o descarga de la } \\
\text { App }\end{array}$ \\
\hline & Adecuación de las instrucciones de manejo (claras y suficientes) \\
\hline & Los enlaces son claramente visibles y explicativos \\
\hline & Se especifican los objetivos \\
\hline & Existe una introducción \\
\hline & Se indica de algún modo la inclusión de material nuevo \\
\hline & $\begin{array}{l}\text { Cuando un enlace conduce a la descarga de un gran archivo gráfico (sonido, vídeo), } \\
\text { se suministra información al usuario avisándole que esto va a ocurrir }\end{array}$ \\
\hline & La App incluye resúmenes / síntesis \\
\hline \multirow{5}{*}{$\begin{array}{l}\text { CONTROL } \\
\text { DESTINATARIOS }\end{array}$} & Posibilidad de controlar la secuencia de la App \\
\hline & La App posibilita retomar la actividad en el punto donde se ha abandonado \\
\hline & Está clara cuál es la audiencia objetivo \\
\hline & Adaptación al currículum \\
\hline & La App se adapta al usuario \\
\hline $\begin{array}{l}\text { NIVEL DE } \\
\text { DIFICULTAD }\end{array}$ & $\begin{array}{l}\text { La App tiene un nivel de dificultad distribuido correctamente de más fácil a más } \\
\text { complejo }\end{array}$ \\
\hline \multirow{7}{*}{ FLEXIBILIDAD } & Posibilidad de adaptación de la App en función de las necesidades del profesor \\
\hline & Posibilidad de adaptación de la App en función de las necesidades del alumno \\
\hline & La App permite añadir nuevos datos \\
\hline & Posibilita incluir modificaciones \\
\hline & El usuario puede elegir el orden que va a seguir \\
\hline & El usuario puede elegir cómo aprender \\
\hline & Versatilidad didáctica: modificable, niveles \\
\hline
\end{tabular}


$\underline{\text { Diseño de una herramienta de evaluación de apps... - C. Gómez, A. Rico y O. Fontal }}$

\begin{tabular}{|c|c|}
\hline \multirow{10}{*}{ INTERACTIVIDAD } & $\begin{array}{l}\text { Existen algún mecanismo de feedback para que los usuarios formulen comentarios } \\
\text { Existe algún mecanismo para que los usuarios soliciten información adicional sobre la } \\
\text { organización }\end{array}$ \\
\hline & Fomentan la participación del profesor \\
\hline & Poseen distintas fórmulas de interacción \\
\hline & Da cabida a las actividades de diseño personal \\
\hline & Posibilidad de manipular el contenido \\
\hline & La interacción (tipo de diálogo, entrada de datos, análisis de respuestas) resulta fluida \\
\hline & La App fomenta la interactividad individual \\
\hline & La App fomenta la interactividad grupal \\
\hline & La App fomenta la interactividad instrumental \\
\hline & La App fomenta la participación del alumno \\
\hline \multirow{28}{*}{ OBJETIVOS } & Se define cuál es el propósito de la App y por qué se produjo \\
\hline & La App define qué metas/objetivos generales cumple \\
\hline & $\begin{array}{l}\text { Entre los objetivos específicos de la App se encuentra la capacidad de estimular, } \\
\text { pertinencia a la necesidad curricular... }\end{array}$ \\
\hline & $\begin{array}{l}\text { La App incluye una descripción de los objetivos de la organización que suministra la } \\
\text { información }\end{array}$ \\
\hline & $\begin{array}{l}\text { La App indica el uso general al que se destina (educativo/instructivo, enseñar, revisar } \\
\text { contenidos...) }\end{array}$ \\
\hline & El propósito de la App está indicado en la pantalla principal \\
\hline & Los objetivos estás explicitados en el programa o la documentación \\
\hline & La estrategia didáctica de la App fomenta el libre descubrimiento \\
\hline & La App permite la función de ejercitar habilidades. \\
\hline & La App permite la función de instruir \\
\hline & La App permite la función de informar \\
\hline & La App permite la función de motivar \\
\hline & La App permite la función de explorar \\
\hline & La App permite la función de entretener \\
\hline & La App permite la función de experimentar/resolver problemas \\
\hline & La App permite la función de crear/expresarse \\
\hline & La App permite la función de evaluar \\
\hline & La App permite la función de procesar datos \\
\hline & La App permite o fomenta la motivación \\
\hline & La App permite o fomenta enseñar destrezas \\
\hline & La App permite o fomenta promover debates \\
\hline & La App permite o fomenta el aprendizaje de conceptos \\
\hline & En la App los objetivos aparecen definidos al inicio de la secuencia didáctica \\
\hline & En la App los objetivos se formulan de manera precisa \\
\hline & En la App los objetivos se adaptan al curriculum \\
\hline & Los objetivos de la App se adaptan al usuario \\
\hline & La App perite la iniciativa individual \\
\hline & La App permite conocer claramente su intención \\
\hline \multirow{3}{*}{$\begin{array}{l}\text { GRADO DE } \\
\text { ATENCIÓN }\end{array}$} & $\underline{\text { La App ayuda a mantener la atención con relación al contenido }}$ \\
\hline & La App ayuda a mantener la atención con relación al diseño \\
\hline & La App mantiene la atención por la calidad técnica \\
\hline \multirow{2}{*}{ VALORES } & La App presenta o potencia algún valor \\
\hline & La App permite modificar actitudes \\
\hline \multirow{7}{*}{$\begin{array}{l}\text { ASPECTOS } \\
\text { COGNITIVOS }\end{array}$} & $\underline{\text { La App facilita la asociación libre de ideas }}$ \\
\hline & La App permite observar \\
\hline & La App permite comparar \\
\hline & La App permite clasificar \\
\hline & La App permite ordenar \\
\hline & La App fomenta la habilidad de visualizar \\
\hline & La App permite el desarrollo de destrezas \\
\hline
\end{tabular}


Tabla 4. Criterios y estándares de la dimensión de Fomento de la creatividad. Fuente: Elaboración propia

\begin{tabular}{|c|c|}
\hline \multicolumn{2}{|c|}{ DIMENSIÓN: FOMENTO DE LA CREATIVIDAD } \\
\hline CRITERIOS & ESTÁNDARES \\
\hline & $\begin{array}{l}\text { Ver: observar/acceder a materiales estáticos, digitales y animados presentados por } \\
\text { docentes, pares, imágenes visuales o multimedia }\end{array}$ \\
\hline & $\begin{array}{l}\text { Observar larga y fijamente: discutir temas que se relacionan con la observación como } \\
\text { presentación natural y estereotipada en el mundo visual }\end{array}$ \\
\hline & Escuchar: grabaciones de presentaciones y conferencias de arte, artistas, historia del arte \\
\hline & $\begin{array}{l}\text { Recopilar: cargar, recopilar y marcar recursos del arte, objetos culturales, materiales, } \\
\text { obras e investigaciones }\end{array}$ \\
\hline & $\begin{array}{l}\text { Intercambiar: ideas sobre la creación del arte y objetos culturales con pares y otras } \\
\text { audiencias }\end{array}$ \\
\hline & $\begin{array}{l}\text { Visualizar: imágenes y recordar experiencias e historias; explorar ideas para organizar } \\
\text { la información usando mapas conceptuales }\end{array}$ \\
\hline & Realizar una tormenta de ideas/diseñar: un torbellino de ideas \\
\hline & $\begin{array}{l}\text { Investigar: leer y explorar información de arte. Se entrevistan, reúnen, analizan y } \\
\text { sintetizan información }\end{array}$ \\
\hline & $\begin{array}{l}\text { Identificar: vocabulario, preguntas e investigaciones relacionados con la historia, } \\
\text { contexto de las obras de arte }\end{array}$ \\
\hline & Jugar: explorar diferentes dimensiones del juego \\
\hline & $\begin{array}{l}\text { Grabar: desarrollar una interpretación o demostración que incluya conceptos orales, } \\
\text { musicales, dramáticos y visuales }\end{array}$ \\
\hline
\end{tabular}

CONCEPTUALIZAR Visitar: realizar viajes virtuales y desarrollar sus propias visitas en forma sincrónica o asincrónica Seleccionar: elegir objetos, materiales, procesos, técnicas y métodos apropiados Practicar:técnicas, métodosyprocesosenartesvisualesenformaindividualocolaborativa Experimentar: manipularyexperimentarcon disciplinas, materiales, formasyconceptos. Desarrollar:representacionesartísticas, usandodiferentesmediospara representarideas Diseñar prototipos: para la fabricación 3D de objetos, esculturas y entornos Elaborar: desarrollar detalles, componentes y conceptos artísticos más complejos Superponer: materiales, métodos y conceptos alrededor de las influencias culturales y sociales en el arte

Traducir: símbolos y metáforas visuales, históricas, espirituales y emocionales

Transformar: objetos y espacios cotidianos en obras de arte Interactuar: explorar interacciones entre conceptos, texto, imágenes, materiales y entornos artísticos

Apropiarse: adoptar, reciclar y/o probar conceptos de la cultura visual Extrapolar: usar detalles específicos para predecir cómo los nuevos métodos y posibilidades artísticos se basarán en conceptos previamente identificados

Yuxtaponer: conceptos, imágenes y otros materiales de diferentes fuentes y/o periodos históricos para crear una obra de arte original

Recombinar: crear mezclas que recombinan diferentes materiales y conceptos

Recontextualizar imágenes y relacionarlas con imágenes, textos y símbolos

Seleccionar varias obras y organizarlas en una muestra de arte o en una recopilación de obras

Diseñar: publicidad, poster, tarjetas

Crear una obra 2D: Pinturas, historietas, caricaturas, técnicas mixtas, impresiones, dibujos, bocetos, fotografías...

CREAR DISEÑAR Crear una obra 3D: diseño de modas, móviles/arte cinético, arte textil, técnicas mixtas...

Crear un portafolio y documentar ideas, obras de arte y otros objetos culturales en formato cuaderno de bocetos y portafolio

Crear un objeto virtual: narraciones, podcasts, arte digital, imágenes digitales, animación, juegos, simulación... 
Diseño de una herramienta de evaluación de apps... - C. Gómez, A. Rico y O. Fontal

Crear un film: recopilar imágenes estáticas, vídeos, música, sonido y narración...

Crear una animación: crear objetos animados en plastilina (claymation), cuadro por cuadro (stopmotion)...

Crear una muestra: crear recopilaciones de obras de arte y objetos culturales en tiempo real

Crear una instalación/obra conceptual: obras, instalaciones, arte in situ y obras no

CREAR DISEÑAR tradicionales de tipo conceptual/experimental/interactivo

Crear un mural: crear y documentar obras públicas y comunitarias in situ

Crear un juego: desarrollar un juego para apoyar el aprendizaje

Sintetizar: combinar temas y conceptos artísticos para crear una obra híbrida

Interpretar: participar en experiencias relacionadas con la improvisación, la

interpretación artística...

Grabar: crear grabaciones basadas en guiones alrededor de conceptos artísticos

Publicar: su obra artística para sí mismos y otros destinatarios

Narrar: relatar historias, desarrollar narraciones y comunicar los conceptos y procesos

implícitos en obras de estilos de arte

Demostrar: procesos de creación de arte y compartir ejemplos

Parafrasear: reformular el significado de obras de arte, imágenes...

Comentar: hacer anotaciones basándose en observaciones y reflexiones relacionadas

DESCRIBIR con conceptos relevantes

Resumir: los estudiantes pueden describir el proceso que les lleva a ciertos resultados

Escribir: blogs, diarios, ensayos, informes, narraciones...

Compartir: expresar pensamientos y sentimientos sobre conceptos y obras

relacionadas con el arte

Presentar: compartir ideas, procesos y/o trabajo artístico

Identificar: vocabulario, conceptos, patrones básicos, significados personales/sociales/

históricos y metáforas en el arte

Clasificar: técnicas artísticas, procesos y conceptos evidentes en obras de acuerdo con

los contenidos

Categorizar: obras de arte según características identificadas

Reflexionar/recordar: sobre una muestra de artes visuales, una serie de obras...

Discutir: participar en diálogos con pares sobre experiencias, ideas, percepciones estéticas, sentimientos...

Conectar: símbolos, metáforas y temas reales o imaginarios en una obra de arte integrada

Comparar/contrastar: estilos, técnicas, elementos y aspectos culturales, sociales,

ANALIZAR/

INTERPRETAR

históricos

Indagar/investigar: cuestiones estéticas, sobre experiencias en artes visuales

Preguntar: construir preguntas de indagación estética, histórica y/o crítica relacionadas

con el material y los conceptos de la asignatura

Responder: preguntas de indagación estética e histórica

Organizar: plantear una lista de temas e ideas antes de comenzar a crear

Representar: sus voces artísticas a través de sus historias personales

Deconstruir: la crítica de arte y los significados convencionales en obras de arte visual

Caracterizar: captar y expresar características distintivas de los procesos y obras de

arte visual

Editar: obras usando distintas herramientas

Revisar: reelaborar y organizar elementos eliminando y/o reemplazando

Comunicar: compartir información sobre los conceptos de arte en relación con la comunicación visual

Evaluar: crear evaluaciones usando distintos formatos

Inventariar: recopilar y organizar obras que tienen similitudes y/o diferencias, comparar y contrastar

EVALUAR Argumentar: debatir y justificar diferentes posturas sobre un tema

Criticar: explicar y articular ideas y responder críticamente a las obras de arte desde una variedad de perspectivas sociales, históricas y contextuales

Juzgar: formar opiniones y emitir juicios sobre el trabajo, evaluaciones entre pares y críticas grupales 
Revista de Humanidades, 39 (2020). p. 61-98. ISSN 1130-5029

Tabla 5. Criterios y estándares de la dimensión de Satisfacción. Fuente: Elaboración propia

\begin{tabular}{|c|c|}
\hline \multicolumn{2}{|c|}{ DIMENSIÓN: SATISFACCIÓN } \\
\hline CRITERIOS & ESTÁNDARES \\
\hline PLACER & Disfrutas cuando utilizas esta App \\
\hline FACILIDAD & Es fácil encontrar ayuda \\
\hline \multirow{4}{*}{$\begin{array}{l}\text { SATISFACCIÓN } \\
\text { ASPECTOS }\end{array}$} & Con la interfaz \\
\hline & Mientras aprendes \\
\hline & Con el texto \\
\hline & Con el sistema de navegación \\
\hline \multirow{5}{*}{$\begin{array}{l}\text { FOMENTO DE LA } \\
\text { CREATIVIDAD }\end{array}$} & Incita al sobreaprendizaje y autodisciplina \\
\hline & Estimula procesos creativos y divergentes \\
\hline & Permite asociaciones libres entre informaciones facilitadas \\
\hline & Propone soluciones a problemas \\
\hline & La App permite realizar todas las fases del proceso creativo \\
\hline \multirow{5}{*}{$\begin{array}{l}\text { PROMUEVE LA } \\
\text { MOTIVACIÓN }\end{array}$} & La App despierta interés \\
\hline & La App es flexible permitiendo la posibilidad de modificar el itinerario de aprendizaje \\
\hline & Genera sentimiento de seguridad \\
\hline & Genera emociones positivas \\
\hline & La App genera que los estudiantes se comprometan con el trabajo solicitado \\
\hline \multirow[t]{3}{*}{ EFECTIVIDAD } & Las tareas se resuelven en un tiempo limitado \\
\hline & Las tareas pueden ser completadas con éxito al primer intento \\
\hline & Permite aprender varias tareas en cada exploración \\
\hline \multirow[t]{2}{*}{ EFICIENCIA } & $\begin{array}{l}\text { El tiempo empleado en completar una tarea es proporcional a la calidad del producto } \\
\text { obtenido }\end{array}$ \\
\hline & El tiempo destinado en la exploración permite obtener resultados positivos \\
\hline \multirow{2}{*}{$\begin{array}{l}\text { SATISFACCIÓN } \\
\text { GENERAL }\end{array}$} & La App resulta fácil de utilizar \\
\hline & La App agrada \\
\hline
\end{tabular}


Diseño de una herramienta de evaluación de apps... - C. Gómez, A. Rico y O. Fontal

ANEXO III: HERRAMIENTA PARA LA VALIDACIÓN POR EXPERTOS.

\begin{tabular}{|c|c|c|c|c|c|}
\hline \multicolumn{6}{|c|}{ GUÍA DE OBSERVACIÓN PARA VALIDAR UNA HERRAMIENTA DE EVALUACIÓN DE APPS } \\
\hline \multirow[t]{2}{*}{ Consideraciones generales } & \multicolumn{5}{|c|}{ Escala:1 es Nada y 5 es Mucho } \\
\hline & 1 & 2 & 3 & 4 & 5 \\
\hline \multicolumn{6}{|c|}{ Las instrucciones orientan claramente para responder el cuestionario } \\
\hline \multicolumn{6}{|l|}{ La secuencia de los ítems es lógica } \\
\hline \multicolumn{6}{|l|}{ La cantidad de ítems es adecuada } \\
\hline \multicolumn{6}{|l|}{ Claridad en la redacción } \\
\hline \multicolumn{6}{|l|}{ Coherencia interna } \\
\hline \multicolumn{6}{|l|}{ Observaciones generales (respuesta abierta cualitativa) } \\
\hline \multicolumn{6}{|l|}{ Sugerencias generales (respuesta abierta cualitativa) } \\
\hline \multicolumn{6}{|l|}{ Usabilidad } \\
\hline \multicolumn{6}{|l|}{ (lista de ítems de dicha dimensión de la herramienta) } \\
\hline \multicolumn{6}{|l|}{ Observaciones generales (respuesta abierta cualitativa) } \\
\hline Sugerencias generales (respuesta abierta cualitativa) & & & & & \\
\hline
\end{tabular}

\section{Adecuación del contenido}

\begin{tabular}{l|l|l|l}
\hline (lista de ítems de dicha dimensión de la herramienta) & & & \\
\hline Observaciones generales (respuesta abierta cualitativa) & & \\
\hline Sugerencias generales (respuesta abierta cualitativa) & &
\end{tabular}

Criterios pedagógicos desde metodologías activas

(lista de ítems de dicha dimensión de la herramienta)

Observaciones generales (respuesta abierta cualitativa)

Sugerencias generales (respuesta abierta cualitativa)

Criterios que fomentan la creatividad desde la educación artística

\begin{tabular}{l|l|l|l}
\hline (lista de ítems de dicha dimensión de la herramienta) & & & \\
\hline Observaciones generales (respuesta abierta cualitativa) & \multicolumn{2}{|l}{} \\
\hline Sugerencias generales (respuesta abierta cualitativa) & & \\
\hline
\end{tabular}

\section{Satisfacción}

\begin{tabular}{l|l|l|l}
\hline (lista de ítems de dicha dimensión de la herramienta) & & & \\
\hline Observaciones generales (respuesta abierta cualitativa) & \multicolumn{2}{|l}{} \\
\hline Sugerencias generales (respuesta abierta cualitativa) & & \\
\hline
\end{tabular}

